\title{
The Willingness to Pay, Accept and Retire
}

\author{
Philipp Schreiber $^{\mathrm{a}}$, Martin Weber ${ }^{\mathrm{a}}$ \\ ${ }^{a}$ University of Mannheim, Department of Banking and Finance \\ L5, 2. 68161 Mannheim, Germany.
}

\begin{abstract}
Today's pay-as-you-go social security systems are put under pressure due to increasing life expectancy, the baby boomers generation entering retirement and a decreasing effective retirement age. In most developed countries workers retire remarkably earlier than the full retirement age, even if economic reasons suggest not to. Conducting a large online survey, this paper relates the willingness-to-accept/ willingness-to-pay disparity to the retirement decision and shows that the presentation of the decision problem strongly influences the outcome. The willingness-to-accept late retirement is more than twice as high as the corresponding willingness-to-pay. We also show that this disparity is driven by loss aversion. Using the reduction in German social security benefits for early retirement as a market price also shows that the presentation in a willingness-to-accept frame can induce early retirement. Results are robust when the analysis is repeated with a representative panel survey for Germany (SAVE panel).
\end{abstract} Keywords: Retirement Decision, Willigness-to-pay, Willigness-to-accept, Social Security

April 2014

\section{Acknowledgements}

We would like to thank the Frankfurter Allgemeine Zeitung for conducting the study with us. Intensive discussion with two journalists, Anne-Christin Sievers and Patrick Bernau, helped to considerably improve the questionnaire. We also would like to thank Sven Nolte for helpful comments and seminar participants at the University of Mannheim for their valuable suggestions.

Email addresses: schreiber@bank.bwl.uni-mannheim.de (Philipp Schreiber), weber@bank.bwl.uni-mannheim.de (Martin Weber) 


\section{Introduction}

40 years ago the time spent in retirement for an average German employee was about 10 years, whereas this number almost doubled until today. The lifespan after retirement steadily increases due to an increasing life expectancy and a decreasing effective retirement age. The decision when to retire and claim social security benefits therefore becomes more and more important as it influences a person's well-being for many years. The German social security system allows people to claim benefits when they first reach the age of 63 . However, similar to the US social security system, retiring before the full retirement age (FRA) of 67 is possible, but results in a constant decrease of pension benefits for the rest of one's life. For example, retiring at age 63 instead of 67 reduces monthly benefits by about $22 \%$, making the retirement decision one of the most economically important decisions in general ${ }^{1}$. Despite the financial incentive to delay retirement and claiming benefits, the majority of workers in most developed countries choose to retire early (see for example Behaghel and Blau, 2012; Gruber and Wise, 2004; Boersch-Supan, 2000). In Germany, for example, more than $65 \%$ of employees retiring in 2011 did so before reaching their full retirement age $^{2}$. This implies that, among other factors, the reduction in monthly social security payments provides not enough incentive to postpone retirement. The price for early retirement therefore is smaller than the reservation price of those individuals.

In this paper, we focus on the reservation price for early retirement. The reservation price for a good can be elicited as the minimum price at which someone would be willing to accept selling the good. Also, the maximum price someone would be willing to pay can be regarded as the reservation price. Standard economic theory predicts that the willingness-to-accept (WTA) and willingness-to-pay (WTP) should not differ if there are no income effects and transaction costs (Willig, 1976). However, there is striking evidence that the WTA can be between 2 and about 100 times larger than the WTP, depending on the good for which reservation prices are elicited (for a detailed overview of the WTA/WTP literature see Horowitz and McConnell, 2002). For example, endowing participants with a coffee mug and eliciting selling prices (WTA)

\footnotetext{
${ }^{1}$ The reduction of $22 \%$ is calculated as the reduction due to retiring earlier than the FRA $(-4$. $3.6 \%=14.4 \%)$ and the reduction due to less accumulated earning points $(\approx 7.6 \%)$. See section 2 for a detailed description.

${ }^{2}$ Source: Statistik der deutschen Rentenversicherung 2012. The FRA for employes retiring in 2011 was 65
} 
leads to reservation prices about twice as high as when participants are asked for a buying price (WTP) for the same mug (Kahneman et al., 1990). This difference is too big to be explained by an income effect, suggesting that the elicitation method of reservation prices directly influences the outcome.

Every worker is naturally endowed with a full and an earliest possible retirement age, where early retirement in this study is considered as tradeable. The price for early retirement is measured in the change in monthly social security benefits. The "market price" in the German social security system for retiring 1 month earlier than the FRA is c.p. $0.3 \%$ of monthly benefits ${ }^{3}$. Depending on whether the full retirement age or an earlier retirement age is used as a reference point, the decision can be seen as a willingness-to-pay or willingness-to-accept problem. The official information by the German government about social security payments includes both, information about payments at the full and the earliest retirement age. This is therefore one of few economically meaningful problems that is naturally presented in a WTA and WTP framework.

To study the WTA/WTP difference in a retirement context, a large online survey in cooperation with one of the biggest German newspapers, "Frankfurter Allgemeine Zeitung" (FAZ), has been conducted (FAZ-survey). Participants answered a set of demographic and retirement related questions. They were randomly assigned to one of two different treatments (between subjects). In the willingness-to-pay treatment subjects indicated the maximum amount of monthly benefits they would be willing to give up in order to retire at the earliest age possible (63) instead of the full retirement age (67). In the willingness-to-accept treatment, in contrast, the minimum increase of monthly payments in order to delay retirement from age 63 to age 67 was elicited. Thereby, in both treatments, participants were given hypothetical monthly benefits as a reference point amounting to $65 \%$ of their current income (level 1). In a consecutive question (within subjects) participants answered the same question again but for a hypothetical pension value of $110 \%$ of their current income (level 2).

Our data shows that the reservation price for early retirement in the WTA treatment is about two times higher than in the WTP treatment. Most important, when compared to the fair price (according to the social security system) the WTA on average lies above the fair price whereas the average WTP is below the fair price indi-

\footnotetext{
${ }^{3}$ Section 2 of this paper provides an overview on how social security benefits are calculated.
} 
cating that early retirement is attractive only in the WTA treatment. Using logistic regression, we find that the probability of retiring early is on average increased by about 17 to 30 percentage points in the WTA treatment. The result is robust to the inclusion of various control variables including risk aversion, loss aversion, financial literacy and planned retirement age. Also results are confirmed using a representative panel survey dataset for Germany (SAVE panel).

In a second step, the cause of the WTA/WTP disparity is analyzed. In most studies, the disparity is attributed to loss aversion (e.g. Thaler, 1980; Kahneman et al., 1990; Bateman et al., 1997). We compare participants self reported loss aversion with their WTA and WTP, respectively. The WTA/WTP ratio indeed increases strongly with loss aversion, however, this increase is caused by a decreasing WTP, the WTA is not influenced by loss aversion. Participants seem to perceive the exchange of money for early retirement as a loss and therefore are willing to pay less the more loss averse they are.

This study contributes to two strands of literature. We show that the WTA/WTP disparity also exists in a retirement context for the good of early retirement. Also, so far there is no study that directly relates an empirical measure of loss aversion to a measure of WTA and WTP. The most important contribution concerns the literature on retirement planing. The majority of past research focuses on economic, socio-economic and health considerations when explaining the retirement decision (e.g. Boersch-Supan, 2000; Lund et al., 2001; Decshryvere, 2006). Other factors beyond economical considerations are often neglected. It seems plausible, however, that behavioral factors, which proof to have a strong influence on retirement saving and planning (see for example Benartzi and Thaler, 2007) also affect the decision when to retire. Thereby, the WTA/WTP disparity is of particular interest for two reasons: 1) policy makers can easily change the presentation format of the retirement decision. For example, in Germany the government provides information about social security benefits by a yearly information letter. Small changes to that letter could change the way people think about the retirement decision (WTA vs. WTP). The same holds for the US Social Security Administration (SSA), which provides information on the impact of different claiming ages. 2) The presentation format has a strong impact. In our study, on average, participants in the WTA scenario implicitly decide to retire early. In contrast, WTP participants implicitly choose to postpone retirement. This effect is significant and survives various robustness tests. Our findings are also in 
line with related studies, which use the planned retirement age as variable of interest. Fetherstonhaugh and Ross (1999) show, that presenting the retirement decision in a loss frame results in significantly higher planned retirement ages. Also Brown et al. (2013) elicit a hypothetical retirement age and find that especially a gain vs. loss frame and different reference ages significantly influence the planned retirement age.

\section{Social Security in Germany}

The German pension system, dating back to 1891, was the first formal pension systems in the world (Coppola and Wilke, 2010). The pay-as-you-go system is based on earnings points (EP) where the accumulated points determine the monthly social security payments after claiming. For each year a person is employed he or she earns points in relation to his or her yearly gross income $\left(E P_{t}=\frac{\text { gross income }_{t}}{\text { average gross income in Germany }{ }_{t}}\right)^{4}$. When claiming social security the sum over all earnings points is multiplied by the current pension value in Germany and an entry coefficient, depending on the persons claiming age ${ }^{5}$. The pension value is determined on the $1^{\text {st }}$ of July each year and amounts to EUR 28.14 for 2013. The entry coefficient equals 1 for people who claim at their full retirement age (FRA) and is decreased by 0.003 for each month a person claims before the FRA. Delaying claiming, however, increases the entry coefficient by 0.005 per month delay. In 2007 the pension system was reformed and a stepwise increase of the FRA from 65 to 67 was resolved. The increase started 2012 for people born after 1946. The FRA is increased from 65 to 66 in steps of one month per year of birth for people being born from 1947 - 1958 and from 66 to 67 in steps of two month per year of birth for people being born from 1959 - 1964. For cohorts born after 1963 the new FRA of 67 is effective ${ }^{6}$. Similar to the German system, claiming social security and leaving the workforce in the US has not to happen at the same time. However, in Germany as well as in the US most people claim social security when leaving the workforce (Greenwald et al., 2010). Therefore, we follow Brown et al. (2013) and keep the survey as simple as possible and do not distinguish between retiring and claiming social security.

\footnotetext{
${ }^{4}$ The EP per year are capped at 2.1066 .

${ }^{5}$ The pension formula is explained in detail in the following legal text: $\S 64$, SGB VI.

${ }^{6}$ For a more detailed view on the German pension system and the 2007 reform see Wilke (2009)
} 


\section{Hypotheses}

\subsection{WTA/WTP}

\section{WTA/WTP Disparity}

In general, a reservation price for a given good can be defined in two ways: 1) as the maximum price a person would be willing to pay for this good or 2) the minimum price a person would demand in order to sell the good. In both cases, the economic rent for the person who buys or sells the good would be zero. Standard theory implies that, neglecting income effects and transaction costs, for most goods the willingnessto-accept should equal the willingness-to-pay (Willig, 1976). However, experimental studies report a significant difference between the WTA and WTP with the WTA being between two and about 100 times larger than the WTP, depending on the type of good (see Horowitz and McConnell, 2002). For example Kahneman et al. (1990) conduct an experiment where half of the subjects are endowed with a Cornell University coffee mug and participants are allowed to trade the mugs among each other. The average minimum selling price (WTA) was more than two times greater than the average maximum buying price (WTP), resulting in a very low trading volume. This effect of high WTA/WTP ratios has been widely observed and on average cannot be explained by an income effect. Horowitz and McConnell (2002) conduct a metaanalysis including 45 studies which all report WTA/WTP ratios significantly greater than one. They find that the high WTA/WTP ratio is not significantly different for real money experiments and hypothetical questions, that the effect is not the result of experimental design features that would be suspect and that for "ordinary market goods" the effect gets weaker ${ }^{7}$.

\section{WTA/WTP and Social Security}

The importance of the WTA/WTP difference is mostly discussed in the context of property rights and environmental policy (see e.g. Horowitz and McConnell, 2002; Knetsch, 1990). However, the retirement context provides an interesting framework as every worker is naturally endowed with a full and earliest possible retirement age. Depending on how retirement information is provided, the decision is framed as a WTA or WTP problem. Assume early retirement is the good of interest for which a reservation price, in form of reduction of monthly payments compared to regular

\footnotetext{
${ }^{7}$ see Horowitz and McConnell (2002) p. 427ff.
} 
retirement, is considered. If the information on how the retirement age will influence benefits takes the full retirement age as a starting point, people are automatically put in a WTP framework. The reference point then would be the full retirement age and the good early retirement would not be "in possession" of the decision maker. Thinking about early retirement, the decision maker has to ask him- or herself "what amount of monthly benefits am I willing to give up in order to retire early". On the other hand, if the earliest possible retirement age is used as a starting point the question would be "what amount of monthly benefits would compensate me for retiring later (working longer)" and the decision would be a WTA problem.

In Germany, the official information about social security payments is provided by the government. It provides information about the current account value, the current monthly benefits and an estimate of monthly benefits at full retirement age. Also the earliest possible date to claim social security and resulting benefits are mentioned and the calculation of benefits is explained (see Appendix A). Depending on which part people put most attention the full or earliest retirement age is salient. Therefore, the retirement decision in Germany is naturally presented in both, a willingness-to-accept and willingness-to-pay frame.

In the US the Social Security Administration (SSA) provides information on the impact of different claiming ages. Until 2008 the approach used by the SSA was the so called "break-even analysis". People were given the amount of monthly benefits they would receive if they claim at the earliest age possible. This is then compared to different later claiming ages with higher monthly benefits and it is calculated how long one has to live to break even (see Brown et al., 2013). This approach puts individuals in a willingness-to-accept frame as the starting or reference point of the analysis is the earliest claiming age possible. Delaying claiming (selling early retirement) increases monthly benefits by some fixed amount (selling price). Since 2009 the SSA uses a more neutral way of presenting information about the social security system. However, according to Brown et al. (2013) the break even analysis is still widely used not only by SSA filed offices but also by private financial advisers.

\subsection{Hypothesis 1}

The WTA/WTP difference has been reported for numerous goods including public or non-market goods (e.g. density of trees, Brookshire and Coursey, 1987), health and safety goods (e.g. health risk of insecticides, Viscusi et al., 1987), ordinary private goods (e.g. coffee mugs, Kahneman et al., 1990), risky and ambiguous lotteries (e.g. 
Eisenberger and Weber, 1995; Harless, 1989) and intangible goods (e.g. travel time, Ramjerdi and Dilln, 2007). In all these studies the WTA/WTP-ratio has been found to be significantly greater than one. Nevertheless, to our knowledge the relation between WTA/WTP has not been studied in a retirement context. It is difficult to assign the good of early retirement to one of the categories mentioned above. On the one hand deciding when to retire has features of a lottery, as it is an intertemporal decision under uncertainty where one does not know how long one will live (and therefore also the time spend in retirement is unknown). On the other hand it also could be considered as a good which affects individuals health status (depending on the kind of employment) which falls in the category of an intangible assets. As the $\frac{W T A}{W T P}$ ratio depends on the kind of good considered, it is difficult to hypothesize about the exact magnitude of the ratio for early retirement. That is why we keep hypothesis 1 as simple as possible and state:

H1a: The reservation price for early retirement in the willingness-toaccept treatment will be significantly higher than the reservation price in the willingness-to-pay treatment.

The difference of our study to the studies of Fetherstonhaugh and Ross (1999) and Brown et al. (2013), who investigate framing effects on the retirement decision, is that we do not ask for a planned or expected retirement age but for a willingness-toaccept or willingness-to-pay for early retirement. This procedure allows us to compare subjects reservation prices with the actuarial fair price. In both treatments (WTA and WTP) a reservation price greater than the fair price indicates that the participant would choose to retire early.

H1b: Participants in the willingness-to-accept treatment are more likely to choose early retirement than participants in the willingness-to-pay treatment.

\subsection{Hypothesis 2}

Even if the WTA/WTP disparity has been studied for almost forty years, the source of the disparity is not well understood. Several explanations have been put forward. Randall and Stoll (1980) and Brookshire et al. (1980) suggest that transaction costs can cause the maximum amount someone would be willing to pay to be smaller than the amount he or she would be willing to accept. They argue that when 
someone builds a price for a good in a WTA treatment, he or she adds the transaction or search costs associated with replacing that good to the reservation price. Other economic explanations that are suggested by Hanemann (1991) are income effects and substitution effects. If the value of the considered good is high, owning the good (WTA) causes an income effect which leads to a higher reservation price. However, WTA/WTP disparity is also found for low value goods like coffee mugs (see Kahneman et al., 1990). Also Horowitz and McConnell (2003) study the income effect as possible explanation and conclude that "[...] the ratio WTA/WTP is too high to be consistent with neoclassical preferences".

As economic reasons lack to fully explain the huge differences between WTA and WTP, also psychological and methodological reasons are studied. Plott and Zeiler (2005) suggest subjects misconception as an alternative explanation. They conduct an experiment, where they simultaneously control for all dimensions of concern over possible subject misconceptions found in the literature and find no difference between elicited WTA and WTP. On the other hand, Loomes and Sugden (1982) argue that ambiguity can cause the WTA/WTP disparity. A risk averse person might increase the selling price of a good if he or she is not sure about its value. Additionally the experiment design itself can possibly cause the effect. In Bateman and Willis (2002) several explanations are put forward. They argue that, among other reasons, an open end question design can cause the observed effect.

The most prominent explanation put forward for the WTA/WTP disparity, however, is an endowment effect in combination with loss aversion. Thaler (1980) called the WTA/WTP disparity an endowment effect stemming from loss aversion. People have a higher reservation price for a good that is in their possession because giving up this good is perceived as a loss. This interpretation is put forward by most WTA/WTP studies (e.g. Thaler, 1980; Knetsch and Sinden, 1984; Coursey et al., 1987; Borges and Knetsch, 1998; Knetsch et al., 2001; Brown, 2005). Surprisingly, to our knowledge, there is no study that relates the WTA/WTP-ratio to a direct measure of loss aversion.

The basic idea is simple: the more loss averse a person is, the less willing he or she is to give up a good in his or her possession. For the WTA/WTP ratio, we therefore hypothesize the following:

H2a: The more loss averse participants are, the higher the WTA/WTP ratio. 
In a second step we focus on the effect of loss aversion on the WTA and WTP separately. The argument put forward by most former studies implies that selling a good creates a loss and buying creates a gain (see Brown, 2005). However, there is an ongoing debate, whether money outlays are also perceived as a loss. Kahneman et al. (1990) and Novemsky and Kahneman (2005) argue that giving up goods, which are intended to be exchanged (e.g. money) are not evaluated as losses. Following this argument loss aversion should only influence the WTA decision. In contrast, Bateman et al. (1997) and Bateman et al. (2005) find that the WTA/WTP disparity is caused by both, loss aversion in the good (WTA) and in money (WTP). To introduce hypothesis 2b we follow the argument of Bateman et al. (1997) and Bateman et al. (2005). Table 1 gives an overview about the hypothesized influence of loss aversion on WTA and WTP.

[Table 1 about here.]

The effect of loss aversion on the WTA should be the opposite of the effect on the WTP.

H2b: The increase of the WTA/WTP ratio in loss aversion is caused by both, an increase of WTA and a decrease of WTP.

\section{Survey Design and Summary Statistics}

\subsection{Survey Design}

\section{Subject Recruitment and General Procedure}

An online survey was conducted from October $14^{\text {th }}$ to November $5^{\text {th }} 2012$ in cooperation with the "Frankfurter Allgemeine Zeitung" (FAZ). The survey covered the field of retirement savings and planing. Summary statistics and control variables are also presented in Schreiber and Weber (2013). Therefore, this section gives a detailed overview of the WTA/WTP related questions and only a brief overview of the summary statistics and control variables.

Subjects were recruited through a link on the newspapers homepage and two announcements (on October $14^{\text {th }}$ and $28^{\text {th }}$ ) in the print edition. 3,077 participants completed the survey in on average eleven minutes. Participants answered hypothetical questions about retirement planning and time preferences, and also data on demographics, risk preferences, financial literacy and some additional controls were 
collected. In particular, the survey asked for a reservation price regarding early retirement in a willingness-to-pay and a willingness-to-accept treatment. We choose hypothetical, non incentivized questions for three reasons: 1) this design allows us to corporate with the FAZ newspaper and recruit a large subject pool. 2) Rubinstein (2001) replicated more than 40 experiments without monetary rewards and in almost all cases there were no qualitative differences in results compared to incentivized experiments. 3) and more specific to our research question Kuehberger et al. (2002) find that framing effects in hypothetical and real decisions do not substantially differ and also Horowitz and McConnell (2002) state that this is also true for the willingnessto-accept/willingness-to-pay difference in particular.

\section{Willingness-To-Accept treatment}

In experimental economics, one has to distinguish between choice based and matching based approaches (see for example Hardisty et al., 2013). Choice methods ask participants to choose between two outcomes. Thereby one of the outcomes is constantly increased (or decreased) to find participants switching point, which is then used to calculate a lower and a upper bound for the variable of interest (e.g. a reservation price, a discount rate, ...). The matching approach in contrast directly asks for indifference points. Participants have to state which outcome would make them indifferent to a second outcome. This has the advantage that not only an upper and lower bound can be calculated. Therefore, in our survey we choose the matching based approach. In the WTA treatment participants are asked to state an amount of money by which their monthly pension payment would have to increase (reservation price) for them to retire 4 years later:

Suppose you have the opportunity to retire at age 63. At this time you would receive a pension of EUR y per month. Please imagine that you would be able to delay retirement by four years and retire at age 67 . This would lead to an increase in monthly pension payments. What would the minimum monthly increase have to be, so that you would be willing to delay retirement from age 63 to age 67 ?

Thereby, the given monthly pension of $y$ depends on participants income. In a first scenario $y$ amounted to $65 \%$ (=level 1) and in a consecutive scenario (within subjects) $y$ was increased to $110 \%$ (=level 2) of participants income. Subjects then entered the amount they additionally demanded. We choose these numbers for two reasons: 1) 
the average monthly social security benefits for an individual, who has been employed for 40 years with an income of 1.5 times the average income for Germany, amounts to about $65 \%$ of his or her monthly income ${ }^{8}$. We choose a higher than average income as a starting point, as the readers of the $F A Z$ typically earn a higher than average income (see Mueller and Weber, 2011). 2) Simply multiplying subjects current income by 0.65 has the disadvantage that real income growth until retirement is neglected and younger participants will face a decision problem with a very low hypothetical pension. Therefore the second question within subjects is introduced for robustness.

\section{Willingness-To-Pay treatment}

In the WTP treatment participants are asked to state an amount of monthly pension payments they would be willing to give up in order to retire 4 years earlier:

Suppose you have the opportunity to retire at age 67. At this time you would receive a pension of EUR y per month. Please imagine that you would be able to speed up retirement by four years and retire at age 63. This would lead to a decrease in monthly pension payments. What maximum amount of monthly pension payments would you be willing to give up in order to be able to retire at age 63 instead of age 67 ?

Thereby, the monthly pension of $y$ was calculated in the same way as for the WTA scenario. In the level 1 (level 2) question $y$ amounted to $65 \%$ (110\%) of participants income. Subjects then entered the amount they would be willing to give up.

\section{Loss aversion}

We use participants self-reported loss attitude to proxy for loss aversion. Earlier studies find that self-reported risk attitude on a Likert scale is a good predictor of actual risk taking (see e.g. van Rooij et al., 2011; Nosic and Weber, 2010). On a seven-point Likert scale participants have to indicate whether they agree to the statement "I'm very afraid of losses" as a measure of loss aversion.

\section{Controls}

\footnotetext{
${ }^{8}$ Monthly benefits are calculated according to the pension formula presented in section 2. This calculation is sensitive to assumptions regarding tax payments, martial status, number of kids and other demographic factors.
} 
Participants risk aversion is elicited similar to loss aversion on a seven-point Likert scale. Participants indicate whether they agree to the statement "I'm a risk averse person". In addition, the planned retirement age is elicited directly, and participants are asked "at what age do you plan to retire?" Participants also answer six financial literacy questions consisting of one of the basic questions from Lusardi and Mitchell (2007), three advanced questions from van Rooij et al. (2011) and two more complicated questions developed by us (see Appendix B). We do so because the FAZ newspaper has a focus on financial markets and previous studies find that subjects with similar characteristics are remarkably financially literate (see Mueller and Weber, 2011). Additional controls are participants subjective life expectancy (elicited directly) and participants indicate if they own private pension insurance as well as how they rate the certainty of social security benefits guaranteed by the government today.

\subsection{Summary Statistics}

Table 2 presents summary statistics. Numer of observations range from 2,142 to 2,297 . The following observations were excluded: Participants who were already retired, participants with zero or missing income ${ }^{9}$ and participants with age below 18.

The average reservation price for early retirement is about EUR 550 per month in the $65 \%$ treatment (level 1) and about EUR 970 in the $110 \%$ treatment (level 2). In both cases the median is considerably lower, indicating a positive skewness (skewness: 5.30 for level 1 and 4.32 for level 2). Also the increase from level 1 to level 2 is almost linear with the mean being 1.77 times greater for level 2 and the hypothetical monthly pension being $\frac{110 \%}{65 \%}=1.69$ times greater. The average planned retirement age of about 64.58 years is close to the former full retirement age in Germany (65).

[Table 2 about here.]

The average age is about 40 years. Men are overrepresented ( $84 \%$ male) reflecting the fact that the majority of FAZ readers are male $(62 \%)$ and that men are more likely to participate in online surveys of our kind (see Mueller and Weber, 2011). Subjects report a relatively high after tax income of about EUR 3,400 (median 3,000)

\footnotetext{
${ }^{9}$ This was necessary as the income was used to calculate a hypothetical pension value, see section 4.1 .
} 
per month (compared to a German average after tax income of about EUR 1,470 in $2011^{10}$ ) and are well educated with $92 \%$ having received the German equivalent to a high school diploma and $68 \%$ having graduated from a university. Half of the participants are married.

Asking participants about their risk- and loss aversion on a 1 to 7 Likert scale leads to an average of 3.87 and 4.32 respectively. As expected, participants did extremely well in standard financial literacy questions with on average 3.51 / 4 correct answers. However, only 0.61 / 2 answers of the additional questions are correct. Directly asking participants about their subjective life expectancy leads to estimates which, with an average of 83.33 years for male participants, are above the average life expectancy in Germany and, with 84.33 for female participants, are close to the average life expectancy. Given the on average wealthier and more educated sample, a self reported life expectancy above the population average is a realistic estimate ${ }^{11}$.

\section{Survey Results}

\subsection{The fair price of early retirement and the fair WTA/WTP disparity}

Analyzing the WTA/WTP disparity in a retirement context has the advantage, that reservation prices can be compared to a fair market price provided by the social security system. However, this also makes things more complicated, as in our survey design the fair price depends on the treatment (WTA vs. WTP). This is best illustrated by a simple example: assume two participants with an income of $W=$ EUR 1,000, whereof one is assigned to the WTA treatment an the other one to the WTP treatment. Both participants are given a hypothetical pension value of $y=0.65 \cdot W=0.65 \cdot 1000=650$ for the level 1 question. According to the German social security formula ( $\S 64$, SGB VI; presented in section 2), it is implicitly assumed that for both participants $650=E P \cdot E C \cdot C P V$ with $\mathrm{EP}$ being the accumulated earning points, EC being the entry coefficient and CPV being the current pension value. To calculate the fair price, three assumptions have to be made: 1) We assume for each participant that he or she has been employed for 40 years when reaching an age of 63.2$)$ it is assumed that the relation between participants income and the

\footnotetext{
${ }^{10}$ Source: German Federal Statistical Office 2012.

${ }^{11}$ For a more detailed description of summary statistics of this survey see Schreiber and Weber (2013)
} 
average income in Germany is constant. Therefore, an additional year of employment increases the earning points by $1 / 40$. 3) A full retirement age of 67 is assumed.

In the WTA treatment the fair price for delaying retirement by four years has to be calculated. The entry coefficient now increases from 0.856 to 1 and the earning points increase by $10 \%$. The fair increase in monthly benefits therefore would be $\frac{1}{0.856} \cdot 1.1-1=28.50 \%$, resulting in EUR 185.3. Correspondingly, the fair decrease in the WTP treatment is calculated as $1-0.856 \cdot \frac{1}{1.1}=22.18 \%$ resulting in EUR 144.2. Therefore, the fair WTA/WTP ratio would be $\frac{185.3}{144.2}=1.285$. This is true for all income levels $W$. We account for this in two ways: 1) the empirically obtained WTA/WTP ratio is compared to the fair ratio of 1.285 and not to a ratio of one. 2) the fair price is included in the regression analysis to test, whether the treatment affects the reservation price beyond the fair price.

\subsection{Hypothesis 1 - the WTA/WTP difference}

Figure 1 presents the reservation price for early retirement of participants in the willingness-to-accept and willingness-to-pay treatment as well as the WTA/WTP ratio and the fair ratio of 1.285 . The average monthly amount participants additionally demand to retire at age 67 instead of age 63 (WTA) is EUR 763.56 if the hypothetical pension value $y$ amounts to $65 \%$ of participants income (Level 1). On the other hand, the monthly amount participants are willing to give up in order to retire at age 63 instead of age 67 (WTP) only amounts to EUR 327.09 at level 1. This difference is highly significant ( $\mathrm{t}$-value of -12.68). The $\frac{W T A}{W T P}$-ratio is 2.33 . The p-value of a Wald test, comparing the WTA/WTP ratio to a ratio of 1.285 , is smaller than 0.0001 . Almost the same picture emerges for the level 2 question where the hypothetical pension value $y$ is increased to $110 \%$ of participants income. The reservation price in the WTA treatment (1275.38) is about 1.9 times higher compared to the WTP treatment (668.66). Again the difference is significant on the 1\%-level (t-value: -9.33, not reported) and the ratio of 1.9 is also significantly higher than 1.285 (Wald test p-value: $<0.0001)$. The small decrease in $\frac{W T A}{W T P}$-ratio from level 1 to level 2 is caused by a disproportional increase of the WTP compared to the increase of $y$. From level 1 to level $2 y$ is increased by $\frac{1.1}{0.65}-1=69.23 \%$. The WTA increases almost proportional $(+67.03 \%)$. However, the WTP increases more strongly from EUR 327.09 to 668.66 $(+104.43 \%)$ causing the $\frac{W T A}{W T P}$-ratio to decline from 2.33 to 1.91 . Results are similar for the median reservation price. For the level 1 treatment a median WTA/WTP ratio of 2.5 is obtained. Also, the ratio declines in the level 2 treatment to 1.5. A 
ratio of about two is on average observed for lotteries (see table IIIA in Horowitz and McConnell, 2002), whereas health and safety goods exhibit a much higher average ratio of about 10. As the good early retirement has features of a lottery our result is in line with the previous literature.

[Figure 1 about here.]

The WTA/WTP difference is further tested in a regression framework. Figure 2 shows the distribution of the reservation price for the full sample (not separated by WTA and WTP) as well as of logarithmized reservation prices for level 1 and 2. The distribution of the reservation price (upper row) resembles the log-normal distribution. Therefore, the logarithmized reservation prices (bottom row) are used in all further regressions ${ }^{12}$.

[Figure 2 about here.]

Columns 2 and 4 of table 3 present coefficients of an OLS regression with the logarithmized reservation price as dependent variable, columns 3 and 5 the corresponding t-values. In addition to the treatment dummy demographic (including the logarithmized fair price) and control variables are included ${ }^{13}$. The main result from figure 1 can be confirmed. For both, level 1 and level 2, the reservation price is significantly higher in the WTA treatment (significant on 1\%-level). This WTA/WTP effect therefore survives the inclusion of the fair price. The interpretation of the magnitude of the effect is not straightforward. For a continuous variable, the coefficient multiplied by 100 gives the percentage effect of that variable on the dependent variable. However, this is not true for dummy variables. Therefore, we calculate effects according to Halvorsen and Palmquist (1980) and Kennedy (1981) ${ }^{14}$. For the level 1 regression (columns 2 and 3 ) this leads to a reservation price for early retirement in the WTA treatment that is $313.55 \%$ higher compared to the WTP treatment ${ }^{15}$. For level 2 (columns 4 and 5 ) the reservation price increases by $110.29 \%$. Therefore, the

\footnotetext{
${ }^{12}$ Participants who indicated a reservation price of 0 EUR are treated as if they indicated a price of 1 EUR and the logarithmized reservation price is set to zero. In section 6 we repeat the analysis without participants who indicate a reservation price of zero.

${ }^{13}$ Participants income is not included in this regression as the fair price by construction is highly correlated (correlation of 0.9899) with income.

${ }^{14}$ The effect is calculated as $\exp \left(\widehat{d}-\frac{1}{2} V(\widehat{d})\right)-1$. With $\widehat{d}$ being the estimated coefficient of the dummy variable and $V(\widehat{d})$ being the variance of the estimate.

${ }^{15} \exp \left(1.4226-\frac{1}{2} 0.077344^{2}\right)-1=313.55 \%$. For all following regressions, with a logarithmized dependent variable, the effect of dummy variables are calculated similarly.
} 
WTA/WTP effect is not only robust to the inclusion of additional variables but also gets stronger in the level 1 regression, as the percentage increase of the reservation price for level 1 is $233 \%$ when only the mean reservation price is taken into account (see figure 1). The treatment influences participants reservation prices beyond the effect it has on the fair price. In summary hypothesis 1a can be confirmed.

[Table 3 about here.]

Besides the treatment, the fair price for early retirement influences participants reservation price. The fair price is calculated depending on participants income. A $1 \%$ increase in the fair price (corresponding to a $1 \%$ increase in income) will increase the reservation price on average by $0.51 \%$ for level 1 and by EUR $0.45 \%$ for level 2 . As for a $1 \%$ increase in income the reservation price increases less strongly $(<1 \%)$, the relative reservation price (reservation price in relation to participants income) decreases with an increase of income. For robustness, we also repeat the analysis with the relative reservation price calculated as $\frac{\text { reservationprice }}{\text { income }}$ and obtain the same results as presented in table 3 (results not reported).

Also, participants who graduated from university indicate a reservation price that is on average $12.13 \%$ (level 1) or $17.84 \%$ (level 2) higher, compared to participants with no university degree. In both regressions being married increases the reservation price. This is in line with Lund et al. (2001) who find that having a partner is a significant predictor of transition to early retirement. In our analysis being married (dummy variable) increases the reservation price for early retirement by $30.94 \%$ (level 1) and $29.78 \%$ (level 2), respectively.

Additionally, only one of the eight control variables proofs to be significant. Participants planned retirement age has a significant and negative effect on the reservation price. For each year a person plans to retire later, the reservation price is decreased by $6.4 \%$ and $5.6 \%$. This effect makes intuitively sense: Participants who have already planned to retire late should have a weaker preference for early retirement compared to a person who plans to retire early and therefore should have a lower reservation price. The effect of loss aversion is not significant in both regressions. However, as it is stated by hypothesis $2 \mathrm{~b}$ that loss aversion influences the WTA and WTP differently, this is not surprising as participants in the WTA and WTP scenario are pooled in these regressions. 


\subsection{Hypothesis $1 b$ - probability of early retirement}

Whether or not the WTA/WTP disparity can induce early retirement depends on the reservation price in relation to the fair price. If the fair price is smaller than the reservation price people are willing to buy the good. The fair price for early retirement can be measured in reduction of monthly social security benefits due to early retirement. Figure 3 shows the average WTA, WTP and the average fair price in both treatments. As the average sample income is high, also high fair prices of 631.22 and 500.05 (level 1) and 1068.23 and 846.24 (level 2) are obtained. The average reservation price in the WTA scenario is for both levels above the average fair price, indicating that under the WTA treatment early retirement seems attractive. In contrast, the average reservation price in the WTP treatment is below the fair price for both scenarios. This gives a first impression on how the WTA/WTP disparity can induce early retirement.

[Figure 3 about here.]

To test hypothesis $1 \mathrm{~b}$ in a regression framework an indicator variable, late retirement, is constructed. For each participant the fair price of early retirement is calculated and compared to his or her reservation price. The indicator equals one if the reservation price is smaller than the fair price, indicating that early retirement is not desirable. For a reservation price higher than the fair price the indicator equals zero. Columns 2 and 4 of table 4 now present coefficients of a logistic regression of late retirement as dependent variable on demographics, the WTA dummy and additional control variables. Columns 3 and 5 present the corresponding z-values. The WTA treatment dummy is highly significant (1\%-level) and negative, indicating that the probability of late retirement decreases if the decision is presented in the WTA treatment. Also in terms of magnitude the effect is strong. The average marginal effect (over all observations) of a change in the WTA dummy is $-29.46 \%$ (level 1) and $-17.84 \%$ (level 2 ), respectively. The probability for retiring late therefore decreases on average by 29.46 (17.84) percentage points in the WTA scenario.

Income and having graduated from university are two out of seven demographic variables with a significant effect in both regressions. Even though income (indirectly measured by the fair price for early retirement) increases the reservation price for early retirement (see table 3 ), it also increases the probability of late retirement. To understand this effect the calculation of the fair price has to be considered. The fair price according to the German pension formula, increases linearly with income. The 
reservation price also increases with income, however, less strongly. Therefore, the positive effect of income on the probability of late retirement is obtained. Previous research also finds that wages are inversely correlated with the acceptance of early retirement (Ruhm, 1989; Kim and Feldman, 1998). The effect of having a university degree on the probability of late retirement is in line with its effect on the reservation price. Participants with a university degree have a higher reservation price for early retirement and are therefore also more likely to retire early. Also, for the planned retirement age the effect is unchanged. The higher the planned retirement age the higher is the probability of late retirement.

[Table 4 about here.]

In summary hypothesis $1 \mathrm{~b}$ can be confirmed. The probability of late retirement is significantly reduced when the decision problem is presented in a willingness-to-accept treatment compared to a willingness-to-pay treatment. Combined with the fact that in Germany as well as in the US information regarding retirement often is presented with the earliest retirement age as a starting point, the WTA/WTP disparity (among many other factors) can help to better understand why people retire on average before the full retirement age.

\subsection{Hypothesis 2a - WTA/WTP ratio and loss aversion}

To analyze the effect of loss aversion on the WTA/WTP ratio, an average reservation price per participant is calculated. As each participant indicates a reservation price in the level 1 question ( $\mathrm{y}=65 \%$ of participants income) and a second reservation price in the level 2 question ( $\mathrm{y}=110 \%$ of participants income) the average reservation price is calculated as $\frac{1}{2}\left(\frac{\text { pricelevel1 }_{\text {le }}}{0.65}+\frac{\text { price level2 }_{2}}{1.1}\right)$, labeled $\overline{W T A}$ and $\overline{W T P}$ respectively.

Participants are then sorted according to their self reported loss aversion. The $\overline{W T A} / \overline{W T P}$ ratio can be calculated as the average $\overline{W T A}$ divided by the average $\overline{W T P}$. Figure 4 graphs the average $\overline{W T A} / \overline{W T P}$ ratio for each of the seven loss aversion categories. Also p-values of a Wald test with the null-hypothesis of the WTA/WTP ratio being equal to 1.285 are reported. Observations in the seven categories range from 60 (loss aversion of 1) to 501 (loss aversion of 5). The $\overline{W T A} / \overline{W T P}$ ratio increases almost monotonically with loss aversion. The lowest ratio of 1.39 is obtained for participants who indicate to be "not at all" loss averse, where the difference between the $\overline{W T A}$ and $\overline{W T P}$ is not statistically significant (t-value of -1.11 , not reported) and also the WTA/WTP ratio is not significantly different from 1.285 
(p-value of 0.7827 ). The $\overline{W T A} / \overline{W T P}$ ratio increases then to 1.87 and 2.32 for participants who indicate a loss aversion of 2 or 3 , respectively. The WTA/WTP ratio is now significantly greater than 1.285 on a $10 \%$ and $1 \%$ level. The ratio drops to 1.83 for participants with a loss aversion of 4 , to increase monotonically afterwards. The highest $\overline{W T A} / \overline{W T P}$ ratio is observed for the most loss averse participants (ratio of 2.70). Also the ratio of 2.70 is significantly greater than the lowest ratio of 1.39 (5\% level, Wald test). Overall, hypothesis 2a is supported as.

[Figure 4 about here.]

\subsection{Hypothesis 2b-WTA, WTP and loss aversion}

According to hypothesis $2 \mathrm{~b}$, the increase in the average $\overline{W T A} / \overline{W T P}$ ratio by loss aversion should be caused by both, an increase in $\overline{W T A}$ and a decrease in $\overline{W T P}$. To get a first impression, figure 5 now displays the average $\overline{W T A}$ and $\overline{W T P}$ separately for each of the seven loss aversion categories. There does not seem to be a relation between loss aversion and the WTA. Therefore, the first part of hypothesis 2a cannot be confirmed by this descriptive analysis. The second part, however, can be confirmed. The average $\overline{W T P}$ strongly decreases with loss aversion. Participants who are "not at all" loss averse indicate on average the highest $\overline{W T P}$ of EUR 1,695. The $\overline{W T P}$ decreases by almost $50 \%$ to EUR 904 for the most loss averse participants.

[Figure 5 about here.]

Table 5 presents results of two OLS regressions, analyzing the $\overline{W T A}$ and $\overline{W T P}$ separately. The dependent variable is the logarithmized $\overline{W T A}$ (Columns 2 and 3) or $\overline{W T P}$ (Columns 4 and 5) per participant, respectively.

[Table 5 about here.]

First, the logarithmized $\overline{W T A}$ is considered. The coefficient for loss aversion is positive, indicating an increase in $\overline{W T A}$ of about $2 \%$ per unit increase in loss aversion. However, the coefficient is insignificant. As suggested by figure 5, loss aversion, therefore, seems to have no effect on the $\overline{W T A}$.

Only one of the six control variables proofs to be significant. The $\overline{W T A}$ decreases by about $5 \%$ for each year a participant plans to retire later. This negative effect is of the same magnitude and significance as for the pooled regressions in table 3. Neither risk aversion, financial literacy, the subjective life expectancy nor owning private 
pension insurance have a significant effect on the $\overline{W T A}$. Also only two demographic variables significantly influence the $\overline{W T A}$. Per $1 \%$ increase of income, the $\overline{W T A}$ is increased by about $0.4 \%$. As the income effect in the pooled regression (table 3 ) is stronger, income seems to effect the $\overline{W T A}$ less than it influences the $\overline{W T P}$. This makes sense, as the income is a upper bound for the WTP (you cannot give up more than all monthly benefits) but not for the WTA. Additionally, being married (dummy) increases the $\overline{W T A}$ by $16.83 \%$.

The second part of table 5 presents OLS regression results for the $\overline{W T P}$. Loss aversion has a highly significant and economically meaningful effect. On average the $\overline{W T P}$ for early retirement decreases by $10.10 \%$ for a one unit increase in self reported loss aversion. The effect is robust to the inclusion of control variables and demographics. Therefore, hypothesis $2 \mathrm{~b}$ can partly be confirmed. Loss aversion increases the $\overline{W T A} / \overline{W T P}$ ratio by significantly decreasing the $\overline{W T P}$. The $\overline{W T A}$, however, is not affected by participants loss aversion. Three out of seven control variables have significant effects on the $\overline{W T P}$. Participants life expectancy as well as their planned retirement age decreases the reservation price in the WTP scenario by about $1 \%$ per additional year. The effect of risk aversion is also significant. More risk averse participants have a higher reservation price for early retirement. This result is in contrast with Coile et al. (2002) who theoretically show that delaying retirement is more attractive with risk aversion.

In contrast to the $\overline{W T A}$, the $\overline{W T P}$ depends highly on participants demographics. Per year of age the $\overline{W T P}$ increases by $1.1 \%$. The closer participants are to retirement, the more they are willing to pay to retire early. The $\overline{W T P}$ increases by about $0.6 \%$ per $1 \%$ increase in income. This effect is about $50 \%$ stronger than for the $\overline{W T A}$. Also being male, being married and having obtained a university degree increases the $\overline{W T P}$. All three effects are economically strong with an increase of $29.15 \%$ (male), $32.62 \%$ (married) and $47.94 \%$ (university degree), respectively.

The explanatory power of the $\overline{W T P}$ regression is more than 3 times as high as for the $\overline{W T A}$ regression (adjusted $\mathrm{R}^{2}$ of $31.53 \%$ vs. $8.34 \%$ ). This is driven by the demographic variables. Even if the income is not included, the adjusted $\mathrm{R}^{2}$ remains by about $20 \%$ (not reported). It seems that the $\overline{W T P}$ highly depends on demographics, whereas the $\overline{W T A}$ seems to be driven by factors that are not captured in our study.

In summary, hypothesis $2 \mathrm{~b}$ can be confirmed only partially. We observe the predicted effect of loss aversion only on the $\overline{W T P}$ but not on the $\overline{W T A}$. In a narrow 
focus this can partly be treated as evidence for the Bateman et al. (1997) and Bateman et al. (2005) argument as we find loss aversion in money. On the other hand, participants may not see the decision as a classic money vs. good problem. The WTP decision could be interpreted as an exchange of distant future consumption for near future leisure. Therefore, as loss aversion clearly exists in consumption (see e.g. Horowitz and McConnell, 2002), our results can also be treated as evidence for the Novemsky and Kahneman (2005) argument. This view can explain why we do not find any loss aversion in the WTA case. The exchange of near future leisure for distant future consumption seems to be perceived as a gain of future consumption. Therefore, loss aversion does not effect the decision.

\section{Robustness}

The robustness of the previous results is analyzed using two datasets. First, the FAZ-survey is used to test robustness regarding the hypothesis 1a. Therefore, a relative measure of the reservation price and an inflated WTP is constructed. In addition, the analysis is repeated with a reduced sample, where participants who indicated a WTP of zero are excluded.

The second dataset comes from a representative panel survey for Germany. The German SAVE panel is conducted since 2001 by the Munich Center for the Economics of Aging (MEA) to understand savings and retirement decisions of German households. The panel focuses on savings behavior, financial assets and old-age provision and includes numerous demographic, economic and psychological characteristics of participating households. Two waves are used: 1) the cross-section of the 2009 wave of the SAVE study where 2,222 households participated and 2) the cross-section of the 2011/2012 wave with 1,660 participants. Two different waves are used as in the 2011/2012 wave some of the control variables are not elicited and therefore, the two waves are merged to get a complete dataset. We are only able to test robustness of hypothesis 1a and 1b, as in the SAVE study 2009 and 2011/2012 no information about participants loss aversion is provided. For a detailed description of the survey methodology (e.g. imputation of missing values) see Boersch-Supan et al. (2009).

\subsection{FAZ-survey}

\section{Relative reservation price}

The relative reservation price used in the following analysis is based on the social security benefits at age 63 . To understand the relative measure we go back to the 
example in section 5.1, where two participants with an income of EUR 1,000 are assigned to the two different treatments. Both participants are given a hypothetical pension value of EUR 650 per month. Assume both participants have the same relative reservation price of for example $+50 \%$ based on benefits at age 63 . This would lead to a absolute reservation price of $650 \cdot 1.5-650=325$ in the WTA treatment and to $650-650 \cdot \frac{1}{1.5}=217$ in the WTP treatment. A WTA/WTP ratio of $\frac{325}{217}=1.5$ would be observed, even if relative reservation prices are equal.

Table 6 presents results of an OLS regression with the logarithmized relative reservation price (based on benefits at age 63) as dependent variable. Columns 2 and 4 present regression coefficients, columns 3 and 5 the respective t-values. Besides the treatment dummy, demographics (including the fair price) and control variables are included. The treatment dummy is highly significant and negative, confirming the results of section 5.2. However, the magnitude of the effect is weaker, compared to the original analysis. The relative reservation price increases by $69.56 \%$ (level 1 ) and $63.36 \%$ (level 2) in the WTA treatment. In addition, the negative effect of the fair price is in line with the previous analysis. An increasing income leads to an increasing fair price. Participants seem to increase their reservation price less strongly, leading to a negative effect of the fair price on the relative reservation price. The absolute reservation price, however, increases with the fair price (see table 3).

[Table 6 about here.]

\section{Inflated WTP}

A second robustness test regarding hypothesis 1a is conducted using an inflated measure of the willingness-to-pay. In the previous analysis it is shown, that the fair WTA/WTP ratio in our survey design is about 1.285. Therefore, the first inflated measure of the WTP is constructed as WTP 1.285 . However, comparing the average WTP in the level 1 and level 2 question in figure 1, it can be seen that the WTP increase more strongly than the hypothetical pension value. The WTP increases by $+104.43 \%$ whereas the hypothetical value only increases by $\frac{1.1}{0.65}-1=69.23 \%$. To account for this "overreaction" a second inflated measure of the WTP is constructed as $W T P \cdot \frac{2.0443}{1.6923} \cdot 1.285=W T P \cdot 1.552$.

Table 7 presents results of four OLS regressions with the logarithmized reservation price as dependent variable. Thereby the WTP is inflated by 1.285 (columns $2-5$ ) and 1.552 (columns 6 - 9) respectively. In all cases the treatment dummy is positive 
and remains significant to the $1 \%$ level, confirming the robustness of hypothesis 1a.

[Table 7 about here.]

\section{Reduced sample}

The last robustness test regarding the FAZ-survey uses only a reduced sample. Indicating a WTP of zero implies that someone would not even be willing to forgo one Euro of monthly pension benefits in order to retire four years earlier. This could for example be due to a high job satisfaction or a really constrained budget. A third reason could be that participants did not want to answer the question and therefore, simply typed in a value of zero. However, since we did not force participants to indicate a reservation price at all (they could also leave the field blank) this explanation seems unlikely. In our sample, 175 (level 1) and 92 (level 2) participants indicated a zero WTP. In contrast, only 27 (level 1) and 47 (level 2) participants indicated a WTA of zero. To analyze whether our results are driven by this difference, the analysis from section 5.2 is repeated without the participants that indicate a WTP of zero. Thereby the average WTP increases from 327.09 to 394.18 (level 1) and from 668.66 to 733.90 (level 2). Table 8 presents the reduced sample regression results. The treatment dummy is significant in both regressions, level 1 and level 2. The overall effect of an increasing reservation price in the WTA treatment is confirmed. However, excluding participants with a WTP of zero weakens the results in two ways: 1) the t-value of the treatment dummy decreases from about 18 to 10 (level 1) and from 9.5 to 3.5 (level 2), respectively. 2) Also the magnitude of the effect decreases strongly. In the level 1 (level 2) regression, being assigned to the WTA treatment now increases the reservation price by only $75.80 \%$ (26.04\%), compared to $313.55 \%$ (110.29\%) for the analysis presented in table 3 . In summary, parts of the significance and magnitude of the WTA/WTP effect in the original analysis is driven by participants which indicate a WTP of zero. However, the main effect remains robust to the exclusion of these participants.

[Table 8 about here.]

\subsection{SAVE Panel}

\section{Robustness SAVE - hypothesis 1a}

Using the SAVE panel for robustness comes with the advantage of a representative sample of the German population. We are able to test whether the results obtained 
in the previous analysis are driven by the fact that FAZ readers present a high income - high education sample. Nevertheless, there are also two drawbacks: 1) the WTA/WTP questions in SAVE are not identical to our questions as they refer to working one year longer or one year shorter compared to a planned retirement age. 2) The questions were not mandatory and therefore, only few participants answered them. However, even if the questions are not identical to our survey, they give a good impression of the robustness of our results.

In the 2011 wave of the SAVE panel the following question for participants who will receive social security benefits in the future was included: "in order to retire one year earlier, would you be willing to give up a part of your monthly benefits?" Participants could then indicate a percentage of their monthly benefits they would be willing to give up or answer with "no" or "I don't know". Of the 1,660 participants 835 were already retired (775) or indicated that they will not receive social security benefits in the future (60). Of the remaining 825 participants, 148 gave a percentage value, 345 indicated that they would not be willing to give up any monthly benefits and 332 answered with "I don't know". We treat this question as a willingness-to-pay scenario as participants indicate a reservation price for early retirement from a perspective where they have to retire later. Only the 148 observations of participants indicating a percentage value are used. A second question, within subjects, in the 2011/2012 SAVE survey is used as willingness-to-accept scenario: "would you be willing to retire one year later if your social security benefits would be increased?" Again participants could indicate a percentage, or answer with "no" and "I don't know". Here 87 participants gave a percentage value, 459 indicated that they would not be willing to work longer, 279 "did not know". Again, only the 87 participants indicating a percentage value enter the analysis. Robustness therefore is tested using the reservation price in percent decrease or increase of monthly social security benefits. Similar to our survey, the SAVE survey includes a set of financial literacy questions (9 questions, see Appendix B), the subjective life expectancy, the planned retirement age and whether or not participants own private pension insurance.

Since the sample presents only a small selection of the whole SAVE dataset, we test whether participants in our sample systematically differ from participants which answered "no" or "I don't know". A logistic regression with an indicator variable that equals one if a participant indicated a percentage value and zero otherwise shows that gender, subjective life expectancy and financial literacy are significant predictors for 
indicating a percentage value (regression results not reported). A mean comparison test confirms these results. There are $54.22 \%$ male participants in the sample indicating a percentage value, whereas only $40.45 \%$ of participants in the "no or I don't know sample" are male. This difference presents a problem insofar as already in the FAZsurvey men are overrepresented and the SAVE dataset is used to test robustness for a more representative sample. However, with $45.78 \%$ of female participants, the SAVE data is by far "more representative" regarding gender. The significant difference in life expectancy and financial literacy is economically weak. Participants who enter a percentage value indicate a life expectancy that is on average only $1.66 \%$ higher compared to the "no or I don't know sample". Also, the average financial literacy is only $6.11 \%$ higher. The small sample does not differ strongly from the representative SAVE dataset and therefore is used to test the robustness of our results.

Figure 6 present the reservation price for early retirement in the SAVE panel under the WTA and WTP treatment as well as the $\frac{W T A}{W T P}$ ratio and the t-statistic of a difference in means test. The average reservation price in the WTA treatment $(23.31 \%)$ is about 3.3 times larger than in the WTP treatment (7.11\%). This difference is highly significant with a t-statistic of -7.05 . The ratio of 3.3 is higher compared to the results in our survey presented in figure 1 . This could be due to the fact that the SAVE question is slightly different. The WTA could be larger because it represents the reservation price for working one additional year compared to the planned retirement age and the WTP is elicited for working one year less than planned (an not for working until planned retirement age).

[Figure 6 about here.]

To analyze the SAVE data in a regression framework the logarithmized percentage values are used ${ }^{16}$. Table 9 presents results of an OLS regression with the logarithmized reservation price as dependent variable and demographic and controls as independent variables.

[Table 9 about here.]

As in the main analysis, the effect of the WTA dummy is positive and highly significant. The reservation price increases on average by $\exp \left(1.1604-\frac{1}{2} 0.1271^{2}\right)-1=$

\footnotetext{
${ }^{16}$ Similar to the absolute EUR values in the FAZ-survey, the percentage values follow a log-normal distribution.
} 
$216.55 \%$ in the WTA treatment. The magnitude of the effect is also comparable to the effect in the main analysis for the level 1 regression (increase of $313 \%$ in the WTA treatment; see table 3). The main result therefore is confirmed using the representative SAVE dataset. In addition, the gender dummy is now significant. $45 \%$ of SAVE participants who indicated a percentage value in the WTA/WTP question are female. In the main analysis (FAZ-survey), this is only true for $16 \%$. The higher variation in the gender dummy may explain the now significant effect. Women seem to have a stronger preference for early retirement and therefore indicate a higher reservation price. This result is in line with Munnell et al. (2004) and Moen and Flood (2013) who report that women are more likely to retire early.

\section{Robustness SAVE- hypothesis $1 b$}

In the German pension system, the percentage increase of social security benefits for an additional year of employment depends on 2 factors: 1) the age of the employee compared to his full retirement age determines whether the benefits are increased by $3.6 \%$ (if the age is at least one year below the full retirement age) or $6.0 \%$ (if the age is equal or greater than the full retirement age). 2) The income in the additional year determines the additional earning points added to the social security account of the employee. The question in the SAVE survey refers to working one year longer or shorter than planned. Therefore, to calculate an indicator for late retirement the planned retirement age and the full retirement age of each participant is taken into account. In the WTA question, participants are asked for a percentage change in social security benefits for working one year longer than planned. If the planned retirement age is equal or greater than the full retirement age the fair price would be $6.0 \%+$ the percentage increase in earning points. For a planned retirement age smaller than the full retirement age the fair price would be $3.6 \%+$ the percentage increase in earning points. The WTP question refers to working one year shorter. Therefore the fair price is $6.0 \%+$ the percentage decrease in earning points if the planned retirement age is greater than the full retirement age and $3.6 \%+$ the percentage decrease in earning points if planned retirement age is smaller or equal to the full retirement age. It is assumed that all participants are employed since the age of 25 and that the income in the additional/deducting year equals the average income. Therefore, the percentage change in earning points is calculated as $\frac{1}{P R A-25}$, with PRA being the planned retirement age. The indicator variable late retirement equals 1 if a participant's reservation price is smaller than his or her fair price and 0 otherwise. 
This indicator equals 1 for 121 of the 239 observations (50.63\%).

Table 10 presents result of a logistic regression with late retirement as dependent variable. Asking participants for an WTA significantly decreases the likelihood of late retirement. The coefficient of -2.690 is significant on the $1 \%$-level. With an average marginal effect over all observations of $-47.43 \%$ percentage points, the effect is also economically strong. The gender dummy has a significant and positive effect. Being male increases the probability for late retirement on average by 11.80 percentage points. The effects of the planned retirement age and owning a private pension insurance are also positive, however, only marginal significant.

In summary, both hypotheses, $1 \mathrm{a}$ and $1 \mathrm{~b}$, can be confirmed using the SAVE dataset. The results therefore, seem not to be driven by more wealthy and highly educated participants in the FAZ survey.

[Table 10 about here.]

\section{Policy Implications}

Pay-as-you-go pension systems of many developed countries are put under pressure through increasing life expectancy, decreasing birthrates and the baby boomers generation entering retirement. As a result, the ratio of working people to retirees is constantly decreasing. Governments of Germany, the US, U.K, France and many other European countries reacted to this development by increasing the full retirement age. This step was necessary as in most countries people retire significant earlier than the full retirement age (see for example Behaghel and Blau, 2012; Boersch-Supan, 2000). Therefore, it is important to understand what drives peoples retirement decision besides the full retirement age.

Before we get to possible policy implications, it has to be analyzed who will be affected by the different treatments of the decision problem. If a participant's WTA is smaller than the price of early retirement, we can assume that his or her decision will not be affected by a different presentation of the problem. This is because a reduction in his or her reservation price would not lead to a different decision and, in general, the WTA is greater than the WTP. The same holds for participants who indicate a WTP that is already greater than the fair price. A participant, therefore, is classified as possibly affected by the presentation of decision problem if the WTA> fair price or $W T P<$ fair price. Following this classification, in the level 1 scenario of the FAZ-survey 1,538 (64.65\%) and in the level 2 scenario 1,469 (59.25\%) participants 
are possibly affected. Therefore, implications are relevant for the majority of participants. A second important issue is the external validity of our results. The income in our sample is significantly higher than the average income in Germany. Therefore it is tested, whether there is a relation between being possibly affected and participants income. A simple mean comparison test shows that the average income of the 1,538 participants who are classified as possibly affected (level 1) is significantly (1\%-level) lower (- 410.62 EUR per month) compared to the not affected group. This result is also confirmed in a logistic regression with demographic and control variables (not reported). A second indication towards the external validity comes from the representative SAVE data. Here the number of participants who are possibly affected is with $70.29 \%$ even bigger compared to the FAZ-survey. Therefore, we conclude that our results have implications for the majority of the population.

The results of this study have two important implications: 1) we find that the WTA/WTP disparity also exists in a retirement context. People on average indicate a reservation price for early retirement which is lower than the fair price if the decision is presented in a WTP context. The opposite is true for the presentation in a WTA context. Policy makers, therefore, should pay massive attention on how they present information about social security payments. 2) As stated above, one way to increase the retirement age is to increase the full retirement age. However, also the social security information letter that is provided by the government represents a powerful tool to increase the effective retirement age. Former studies show that already small changes in a presentation format can lead to different decisions (e.g. Choi et al., 2013). Combined with the results of this study, policy makers should consider changes in the information letter as a second device, next to increasing the full retirement age.

\section{Conclusion}

This paper relates the retirement decision with the willingness-to-accept/willingnessto-pay disparity. In an online survey participants indicate their reservation price for early retirement as their WTA or WTP, respectively. In line with the WTA/WTP literature, we find that the WTA is about two times greater than the WTP. When comparing the market price for early retirement, measured as reduction of monthly social security benefits according to the German pension system, with participants reservation price, we find that early retirement seems especially attractive for participants answering the WTA question. The average probability of early retirement is 
about 28-37 percentage points higher when the reservation price is elicited as a WTA compared to a WTP. Additionally, we analyze the cause of the high WTA/WTP ratio. Loss aversion significantly increases the ratio, however, not by increasing the WTA but by decreasing the WTP. This finding is in contrast with the most prominent explanation for the WTA/WTP disparity, namely an endowment effect caused by loss aversion. Participants seem to perceive the exchange of money for early retirement as a loss and therefore are willing to pay less the more loss averse they are. Giving up early retirement in exchange for money, however, is not perceived as a loss and loss aversion has no significant effect on the WTA. 
Bateman, I., A. Munro, B. Rhodes, Borges, B. F. and J. L. Knetsch. 1998. Tests

C. Starmer, and R. Sugden. 1997. A test of the theory of reference-dependent preferences. The Quarterly Journal of Economics 112 (2): 479-505.

Bateman, I., D. Kahneman, A. Munro, C. Starmer, and R. Sugden. 2005. Testing competing models of loss aversion: an adversarial collaboration. Journal of Public Economics 89 (8): 1561-1580.

Bateman, I. J. and K. G. Willis (Editors). 2002. Valuing Environmental Preferences: Theory and Practice of the Contingent Valuation Method in the US, EU, and developing Countries. Oxford University Press, USA.

Behaghel, L. and D. M. Blau. 2012. Framing social security reform: Behavioral responses to changes in the full retirement age. American Economic Journal: Economic Policy 4 (4): 41-67.

Benartzi, S. and R. H. Thaler. 2007. Heuristics and biases in retirement savings behavior. Journal of Economic Perspectiv 21 (3): 81-104.

Boersch-Supan, A. 2000. Incentive effects of social security on labor force participation: evidence in germany and across europe. Journal of Public Economics 78 (12): 25-49.

Boersch-Supan, A., M. Coppola, L. Essig, A. Eymann, and D. Schunk. 2009. The German SAVE study design and results. Munich Research Institute for the Economics of Aging . of market outcomes with asymmetric valuations of gains and losses: Smaller gains, fewer trades, and less value. Journal of Economic Behavior $\&$ Organization 33 (2): 185-193.

Brookshire, D. S. and D. L. Coursey. 1987. Measuring the value of a public good: An empirical comparison of elicitation procedures. The American Economic Review 77 (4): 554-566.

Brookshire, D. S., A. Randall, and J. R. Stoll. 1980. Valuing increments and decrements in natural resource service flows. American Journal of Agricultural Economics 62 (3): 478-488.

Brown, J. R., A. Kapteyn, and O. S. Mitchell. 2013. Framing effects and expected social security claiming behavior. Journal of Risk and Insurance forthcoming.

Brown, T. C. 2005. Loss aversion without the endowment effect, and other explanations for the wtawtp disparity. Journal of Economic Behavior \& Organization 57 (3): 367-379.

Choi, J. J., E. Haisley, J. Kurkoski, and C. Massey. 2013. Small cues change savings choices. NBER working paper No. 17843.

Coile, C., P. Diamond, J. Gruber, and A. Jousten. 2002. Delays in claiming social security benefits. Journal of Public Economics 84 (3): 357-385. 
Coppola, M. and C. B. Wilke. 2010. How sensitive are subjective retirement expectations to increases in the statutory retirement age? the german case. MEA Discussion Paper 207-10.

Coursey, D. L., J. L. Hovis, and W. D. Schulze. 1987. The disparity between willingness to accept and willingness to pay measures of value. The Quarterly Journal of Economics 102 (3): 679-690.

Decshryvere, M. 2006. Health and retirement decisions: An update of the literature. ENEPRI Research Reports 6 (1): 132.

Eisenberger, R. and M. Weber. 1995. Willingness-to-pay and willingness-toaccept for risky and ambiguous lotteries. Journal of Risk and Uncertainty 10 (10): 223-233.

Fetherstonhaugh, D. and L. Ross. 1999. Framing Effects and Income Flow Preferences in Decisions about Social Security. In: Behavioral Dimensions of Retirement Economics. Washington DC: Brookings Institution Press and Russell Sage Foundation.

Greenwald, M., A. Kapteyn, O. S. Mitchell, and L. Schneider. 2010. What do people know about social security? RAND Working Paper WR-792-SSA.

Gruber, J. and D. A. Wise. 2004. Social Security Programs and Retirement around the World: Micro-Estimation. University Of Chicago Press, 1 edition.
Halvorsen, R. and R. Palmquist. 1980 The interpretation of dummy variables in semilogarithmic equations. The American Economic Review 70 (3): 474-475.

Hanemann, W. M. 1991. Willingness to pay and willingness to accept: How much can they differ? The American Economic Review 81 (3): 635-647.

Hardisty, D. J., K. F. Thompson, D. H. Krantz, and E. U. Weber. 2013. How to measure time preferences: An experimental comparison of three methods. Judgment and Decision Making 8 (3): 236-249.

Harless, D. W. 1989. More laboratory evidence on the disparity between willingness to pay and compensation demanded. Journal of Economic Behavior $\mathcal{E}$ Organization 11 (3): 359-379.

Horowitz, J. K. and K. McConnell. 2003. Willingness to accept, willingness to pay and the income effect. Journal of Economic Behavior \& Organization 51 (4): 537-545.

Horowitz, J. K. and K. E. McConnell. 2002. A review of WTA / WTP studies. Journal of Environmental Economics and Management 44 (3): 426-447.

Kahneman, D., J. L. Knetsch, and R. H. Thaler. 1990. Experimental tests of the endowment effect and the coase theorem. Journal of Political Economy 98 (6): 1325-1348.

Kennedy, P. E. 1981. Estimation with correctly interpreted dummy variables in 
semilogarithmic equations. The American Economic Review 71 (4): 801-.

Kim, S. and D. C. Feldman. 1998. Healthy, wealthy, or wise: Predicting actual acceptances of early retirement iincentive at three points in time. Personnel Psychology 51 (3): 623-642.

Knetsch, J. L. 1990. Environmental policy implications of disparities between willingness to pay and compensation demanded measures of values. Journal of Environmental Economics and Management 18 (3): 227-237.

Knetsch, J. L. and J. A. Sinden. 1984. Willingness to pay and compensation demanded: Experimental evidence of an unexpected disparity in measures of value. The Quarterly Journal of Economics 99 (3): 507-521.

Knetsch, J. L., F.-F. Tang, and R. Thaler. 2001. The endowment effect and repeated market trials: Is the vickrey auction demand revealing? Experimental Economics 4 (3): 257-269.

Kuehberger, A., M. Schulte-Mecklenbeck, , and J. Perner. 2002. Framing decisions: Hypothetical and real. Organizational Behavior and Human Decision Processes 89 (2): 1162-1175.

Loomes, G. and R. Sugden. 1982. Regret theory: An alternative theory of rational choice under uncertainty. The Economic Journal 92 (368): 805-824.

Lund, T., L. Iversen, and K. B. Poulsen. 2001. Work environment factors, health, lifestyle and marital status as predictors of job change and early retirement in physically heavy occupations. Am. J. Ind. Med. 40 (2): 161-169.

Lusardi, A. and O. S. Mitchell. 2007. Baby boomer retirement security: The roles of planning, financial literacy, and housing wealth. Journal of Monetary Economics 54 (1): 205-224.

Moen, P. and S. Flood. 2013. Limited engagements? womens and mens work/volunteer time in the encore life course stage. Social Problems 60 (2): 206233.

Mueller, S. and M. Weber. 2011. How good are mutual fund ratings and can they be improved? - empirical evidence for finanztest. European Financial Management Forthcoming.

Munnell, A. H., R. K. Triest, and N. A. Jivan. 2004. How do pensions affect expected and actual retirement ages? CRR Working $P a$ per 27.

Nosic, A. and M. Weber. 2010. How risky do i invest: The role of risk attitudes, risk perceptions, and overconfidence. Decision Analysis 7 (3): 282-301.

Novemsky, N. and D. Kahneman. 2005. The boundaries of loss aversion. Journal of Marketing Research 42 (2): 119-128.

Plott, C. R. and K. Zeiler. 2005. The willingness to pay-willingness to accept gap, the "endowment effect," subjectmisconceptions, and experimental procedures for 
eliciting valuations. The American Economic Review 95 (3): 530-545.

Ramjerdi, F. and J. L. Dilln. 2007. Gap between willingness-to-pay (wtp) and willingness-to-accept (wta) measures of value of travel time: Evidence from norway and sweden. Transport Reviews 27 (5): 637-651.

Randall, A. and J. R. Stoll. 1980. Consumer's surplus in commodity space. The American Economic Review 70 (3): 449-455.

Rubinstein, A. 2001. A theorist's view of experiments. European Economic Review 45 (4-6): 615-628.

Ruhm, C. J. 1989. Why older americans stop working. The Gerontologist 29 (3): 294-299.

Schreiber, P. and M. Weber. 2013. Time inconsistent preferences and the annuitization decision. Working Paper .
Thaler, R. H. 1980. Toward a positive theory of consumer choice. Journal of Economic Behavior and Organization 1 (1): 39-60.

van Rooij, M., A. Lusardi, and R. Alessie. 2011. Financial literacy and stock market participation. Journal of Financial Economics 101 (2): 449-472.

Viscusi, W. K., W. A. Magat, and J. Huber. 1987. An investigation of the rationality of consumer valuations of multiple health risks. The RAND Journal of Economics 18 (4): 465-479.

Wilke, C. B. 2009. German Pension Reform: On Road Towards a Sustainable Multi-Pillar System (Sozialokonomische Schriften). Peter Lang GmbH.

Willig, R. D. 1976. Consumer's surplus without apology. The American Economic Review 66 (4): 589-597. 
Appendix A. Social Security Information

[Figure 7 about here.]

[Figure 8 about here.]

[Figure 9 about here.]

\section{Appendix B. Financial Literacy Questions}

[Figure 10 about here.]

[Figure 11 about here.] 
Figure 1: WTA/WTP ratio and average reservation price for early retirement depending on the treatment (WTA vs. WTP) and level (65\% or $110 \%)$

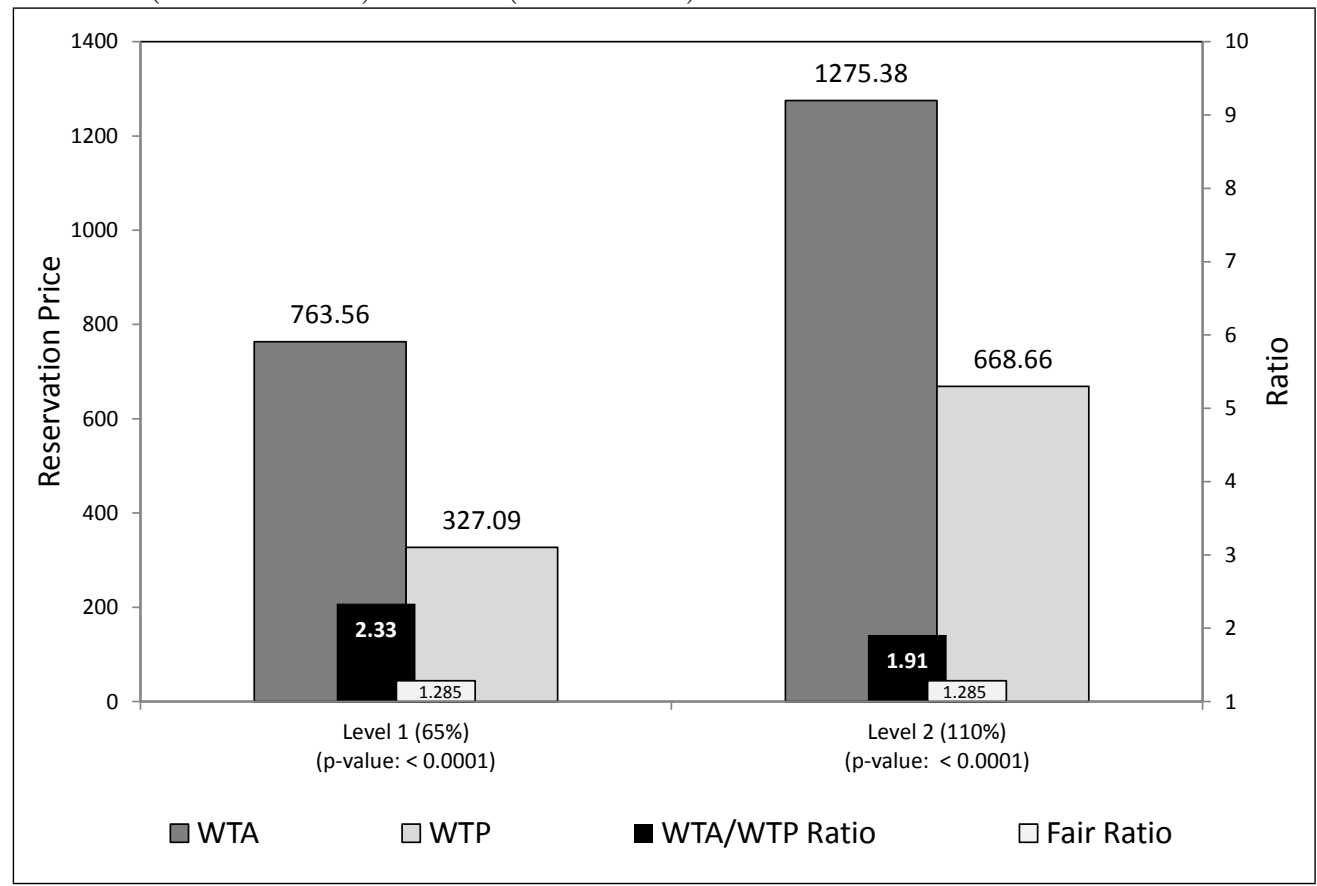


Figure 2: Distribution of the dependent variable, reservation price [EUR] and logarithmized reservation price $[\mathrm{EUR}]$, by level.
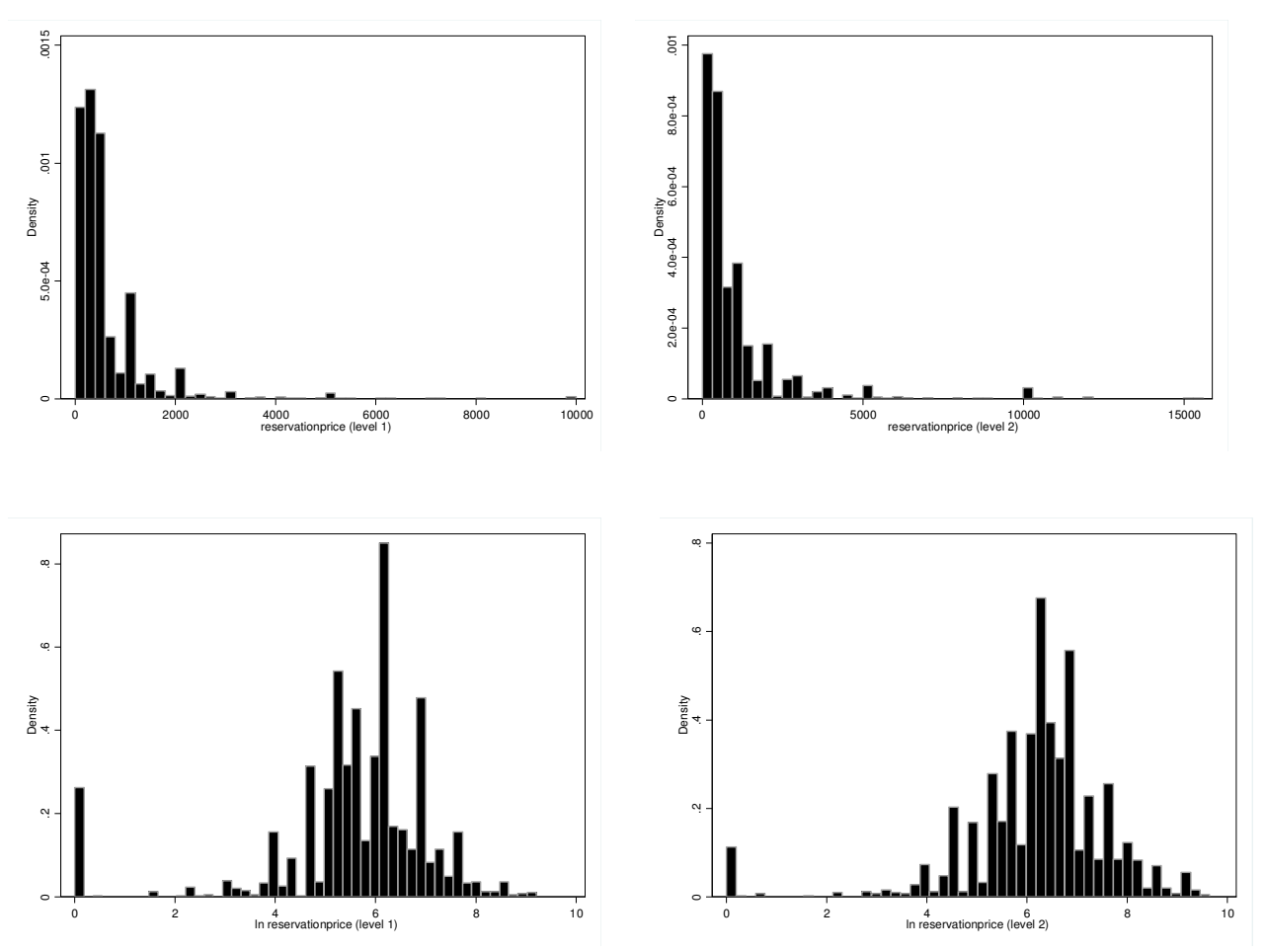
Figure 3: Fair price and average reservation price for early retirement depending on the treatment (WTA vs. WTP) and level $(65 \%$ or $110 \%)$

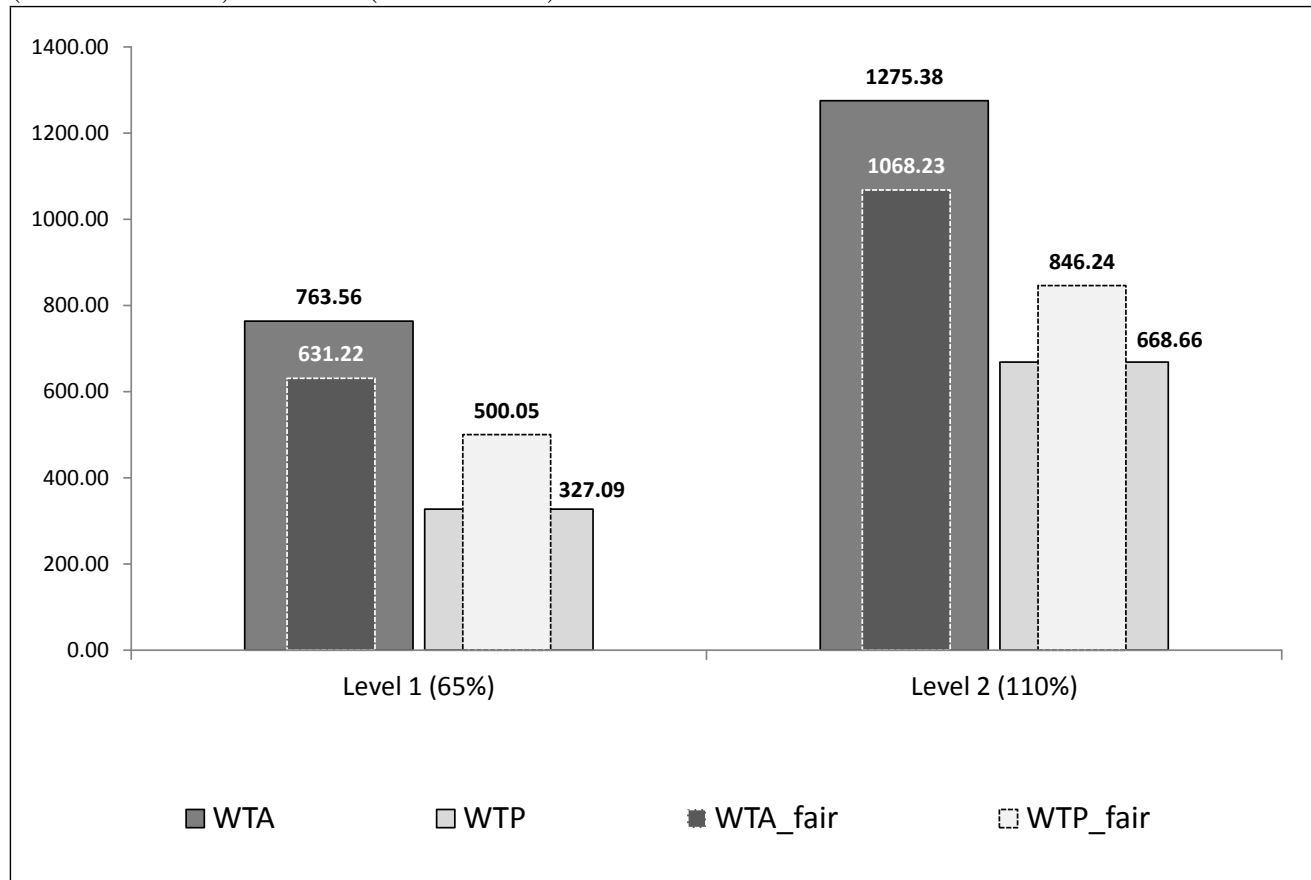


Figure 4: Average $\overline{W T A} / \overline{W T P}$ ratio by loss aversion

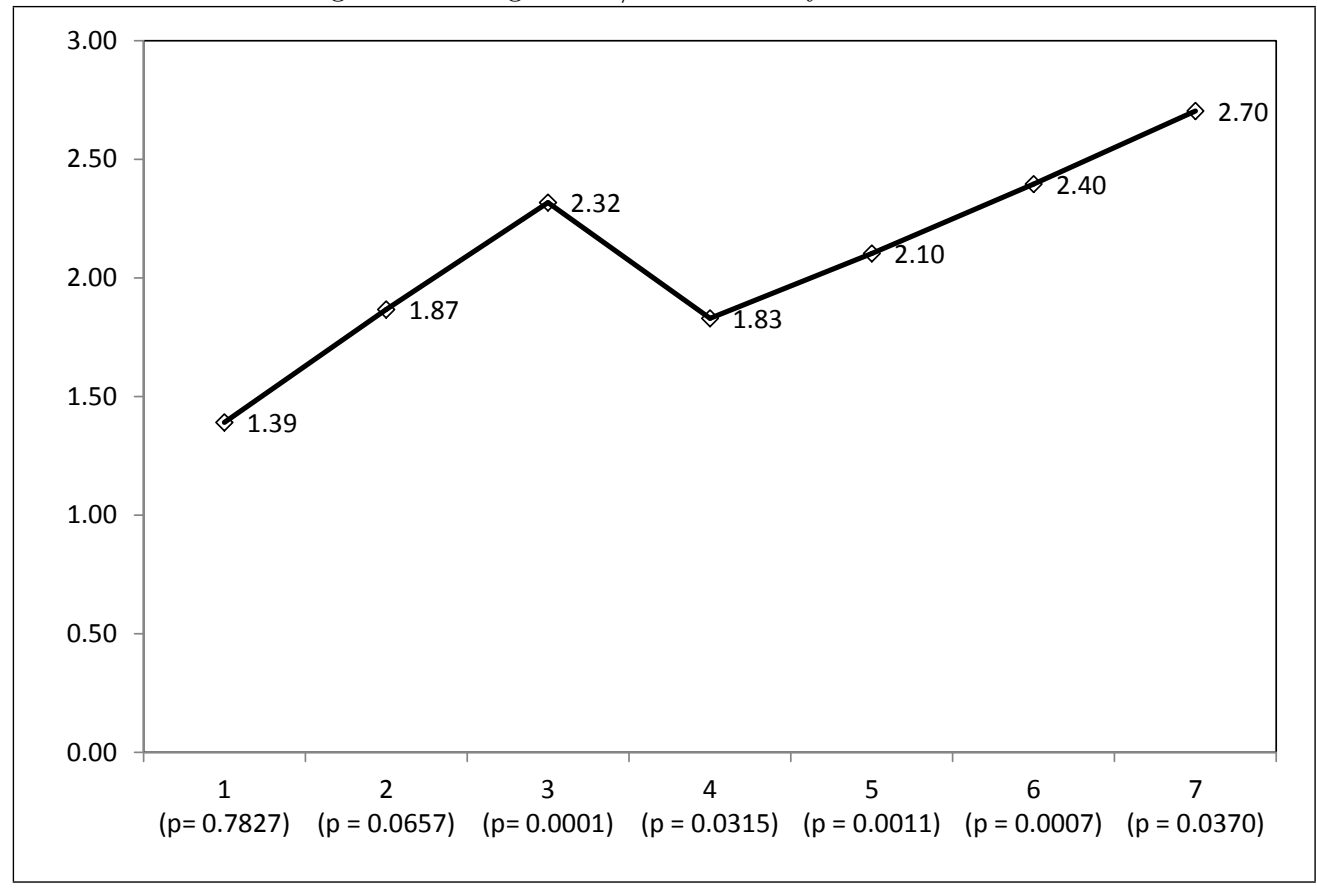


Figure 5: Average $\overline{W T A}$ and $\overline{W T P}$ by loss aversion

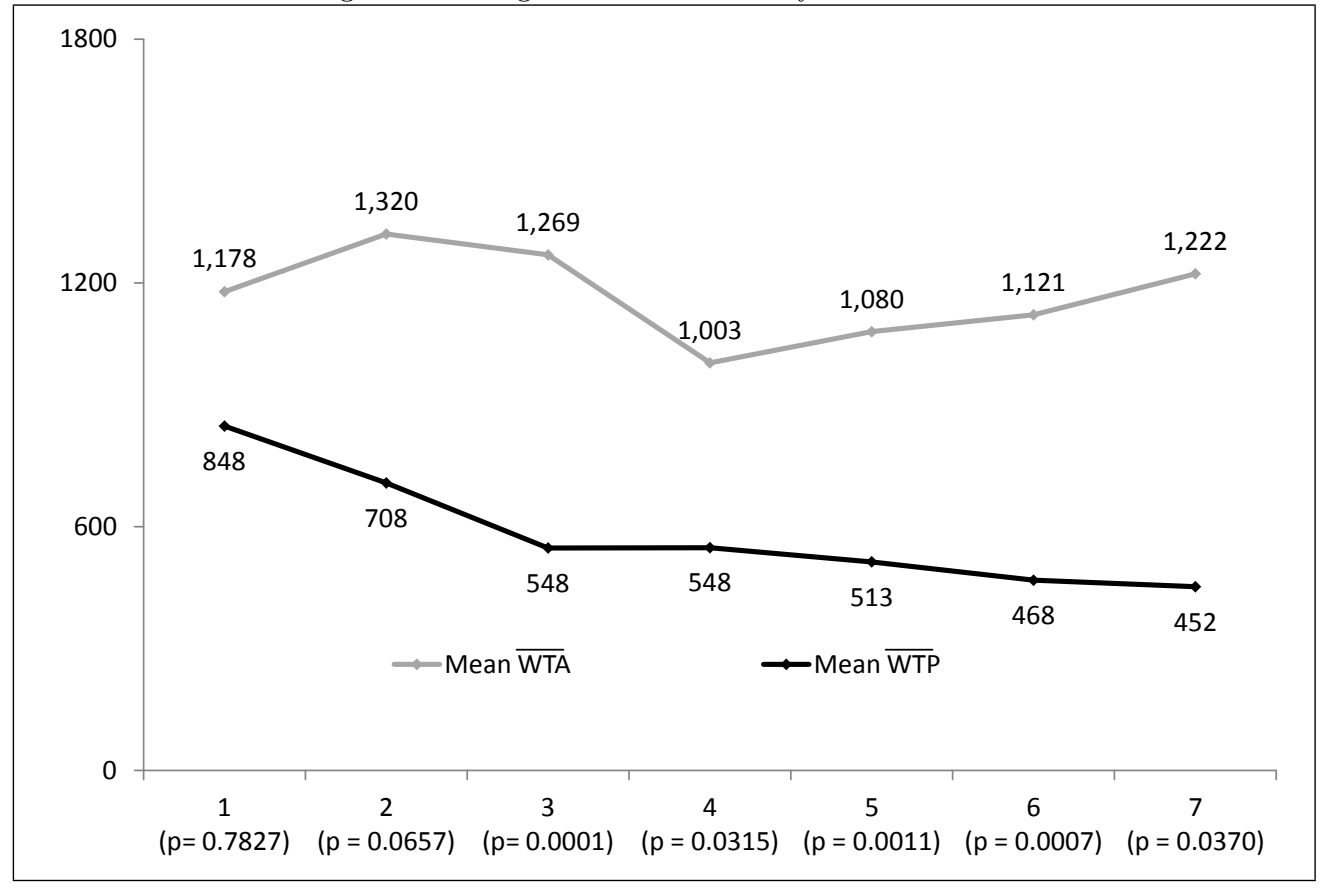


Figure 6: WTA/WTP ratio and average reservation price (in per cent of monthly social security benefits)) for early retirement depending on the treatment (WTA vs. WTP). Data used for robustness is from the German SAVE panel, waves 2009 and 2011/2012.

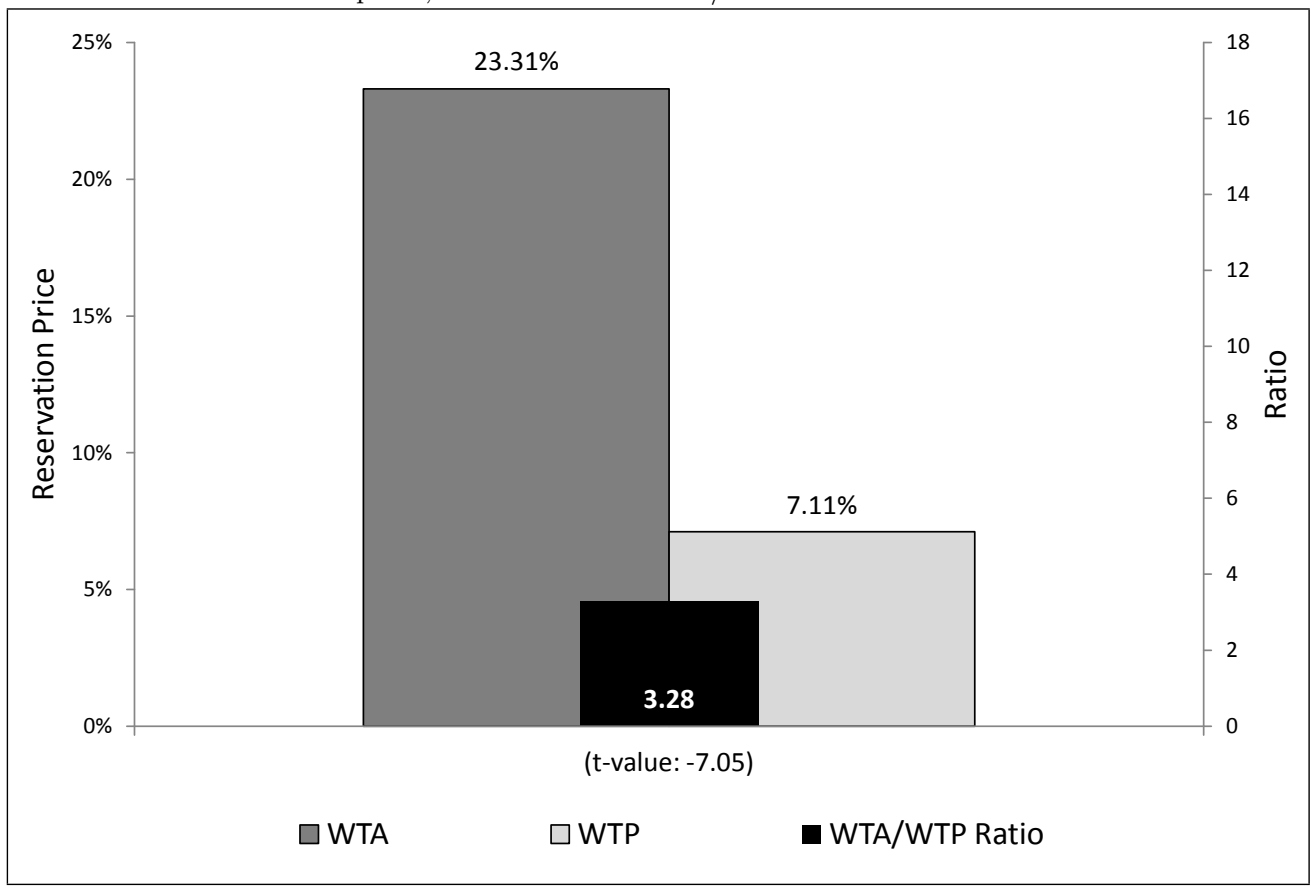


Figure 7: Page 1 of the social security information letter with short translation.

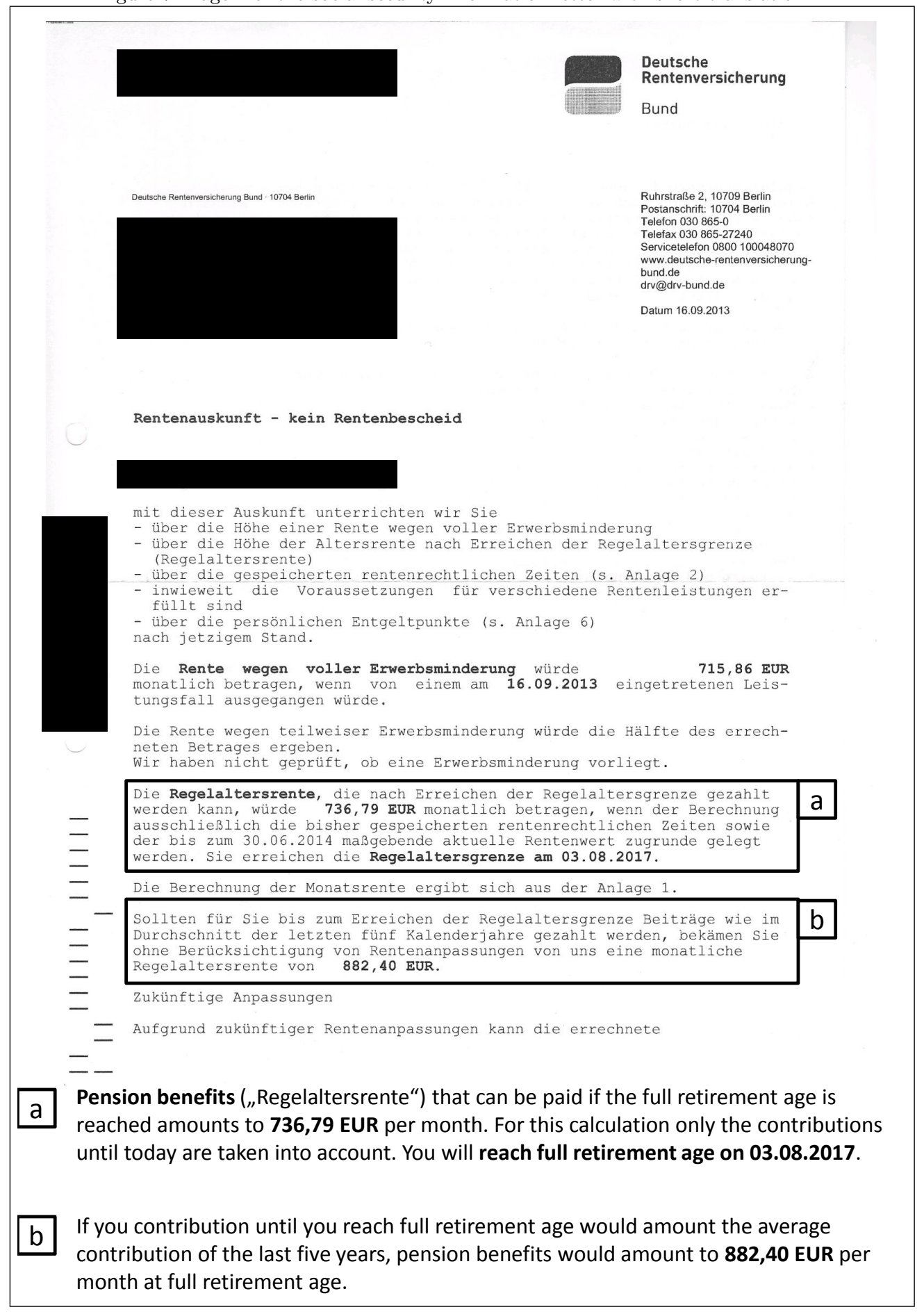


Figure 8: Page 5 of the social security information letter with short translation.

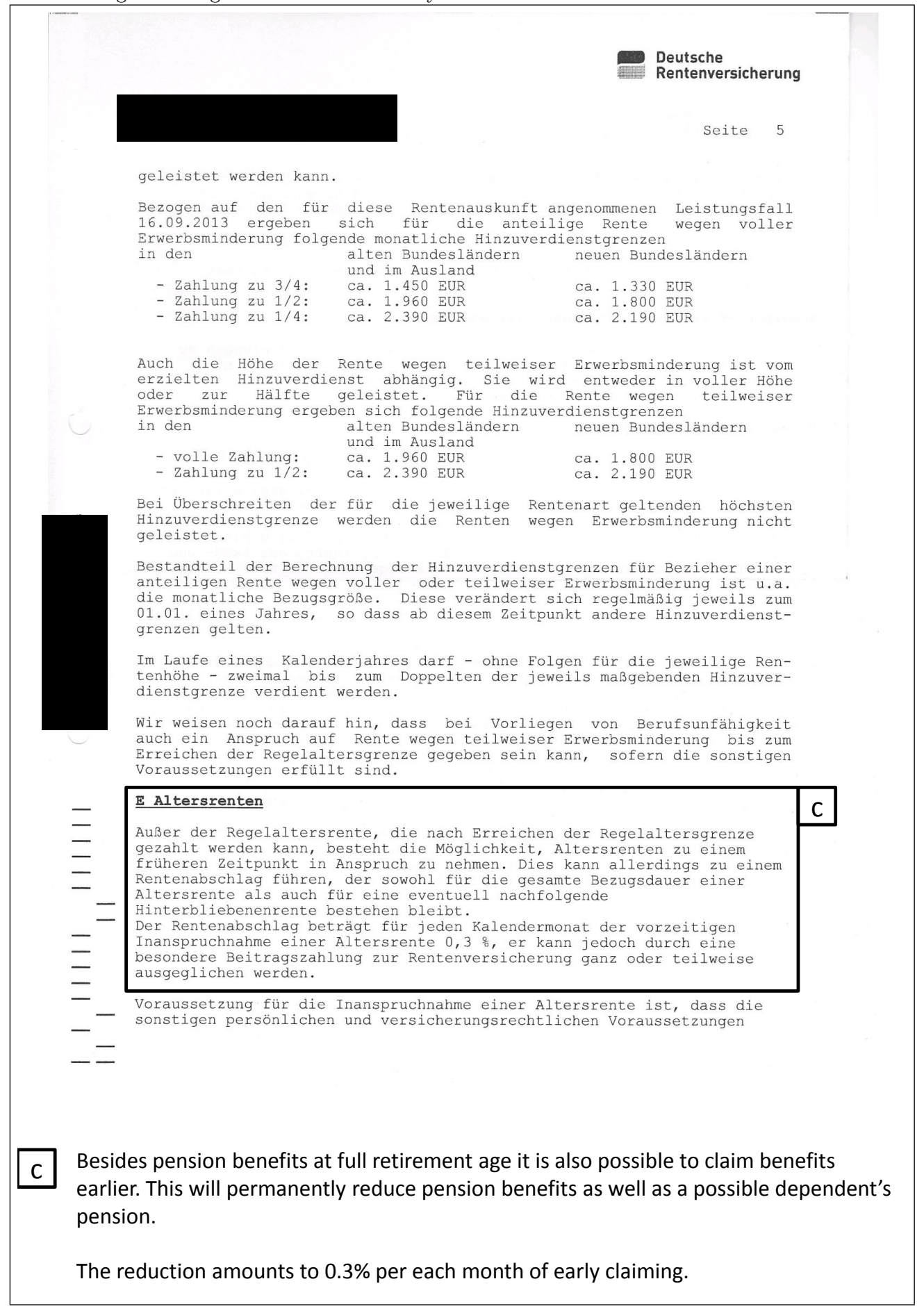


Figure 9: Page 8 of the social security information letter with short translation.

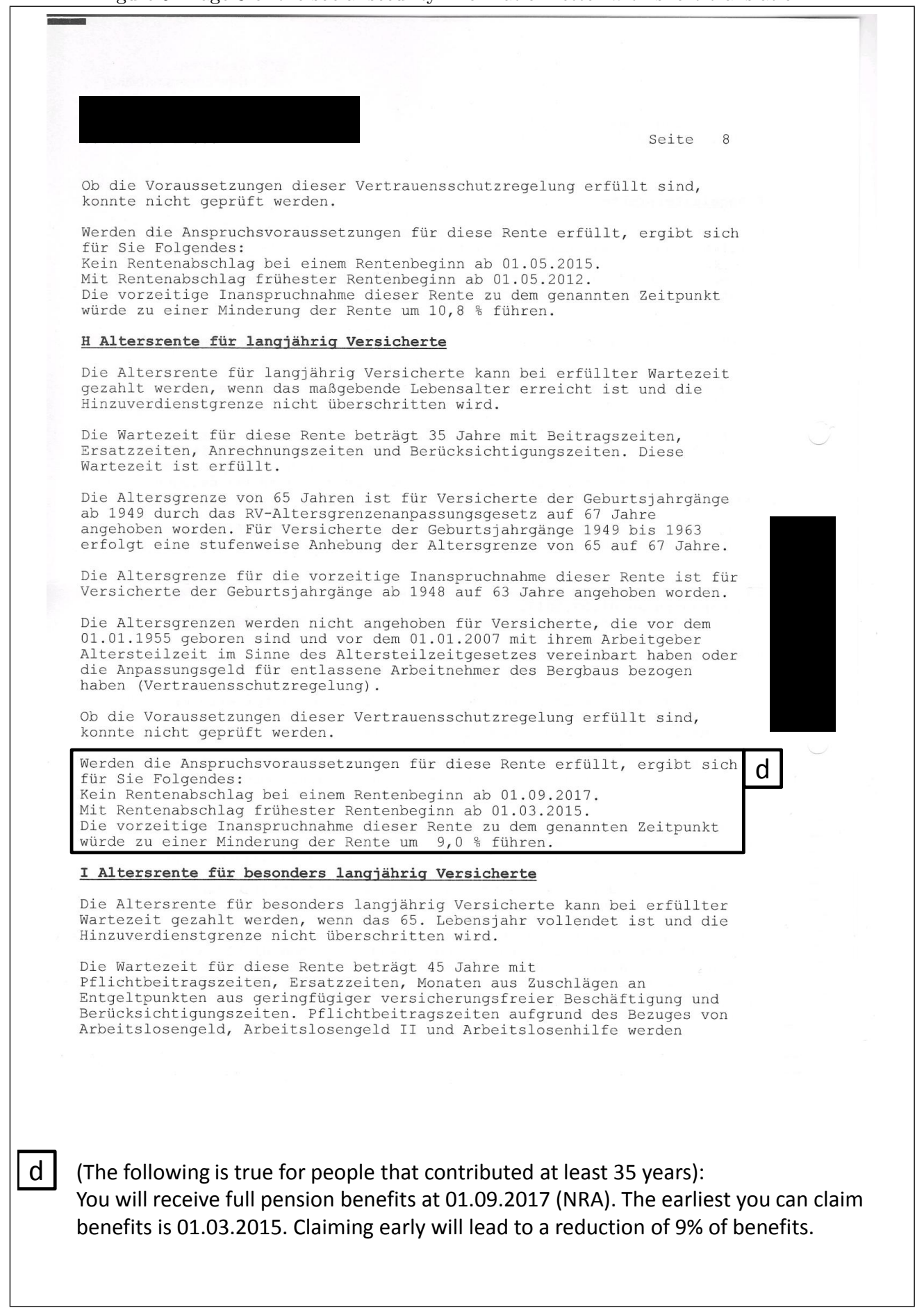


Figure 10: Financial literacy questions 1-6 in the FAZ survey.

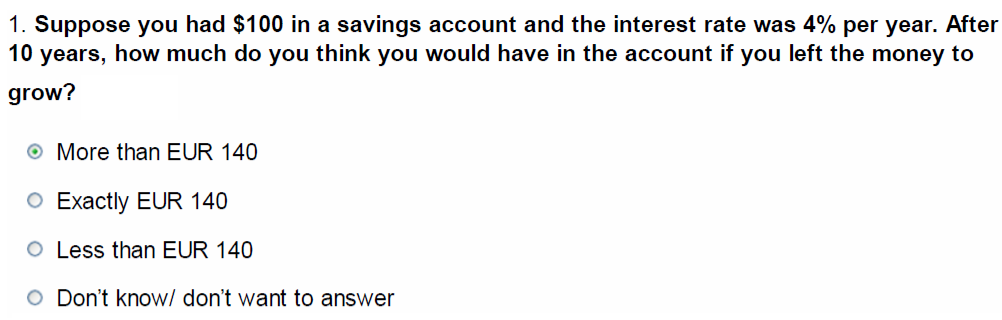

2. Normally, which asset displays the highest fluctuations over time?
Savings accounts
○onds
• Stocks
- Don't know/ don't want to answer

3. Which of the following statements is correct?
Once one invests in a mutual fund, one cannot withdraw the money in the first year
- Mutual funds can invest in several assets, for example invest in both stocks and bonds
- Mutual funds pay a guaranteed rate of return which depends on their past performance
None of the above
- Don't know/ don't want to answer

4. Consider a call-option with a stock as underlying. Please judge the following statement: "The price of the call-option should increase if the volatility of the underlying stock increases"

(-) The statement is true

The statement is false

- The statement can't be judged with the information given

- Don't know/ don't want to answer

5. If the interest rate falls, what should happen to bond prices?

○ Rise

○ Fall

- Stay the same

- Don't know/ don't want to answer

6. What is measured by a stocks "beta"?
The stocks book to market value
- The stocks volatility
- The sensitivity of the stock price to price changes of a benchmark index
- None of the above
o Don't know/ don't want to answer 
Figure 11: Financial literacy questions 1-9 in the SAVE 2009 survey.

1. Suppose you have $€ 100$ in a savings account earning 2 percent interest a year. After five years, how much would you have?

- More than $€ 102$.

- Exactly $€ 102$.

- Less than $€ 102$.

- Don't know.

2. Suppose you have $€ 100$ in a savings account earning 20 percent interest a year. After five years, how much would you have?

- More than $€ 200$.

- Exactly $€ 200$.

- Less than $€ 200$.

- Don't know.

3. Imagine that the interest rate on your savings account is 1 percent a year and inflation is 2 percent a year. After one year, would the money in the account buy more than it does today, exactly the same or less than today?

- More.

- Same.

- Less.

- Don't know.

4. Suppose that in the year 2012, your income has doubled and prices of all goods have doubled too. In 2012, how much will you be able to buy with your income?

- More than today.

- The same.

- Less than today.

- Don't know.

5. Normally, which asset displays the highest fluctuation over time?

- Savings account.

- Bonds.

- Stocks.

- Don't know.

6. Which of the following statements describes the main function of the stock market?

- The stock market helps to predict stock earnings.

- The stock market results in an increase in the price of stocks.

- The stock market brings people who want to buy stocks together with those who want to sell stocks.

- None of the above.

- Don't know.

7. Buying a company stock usually provides a safer return than a stock mutual fund. True or false?

- True.

- False.

- Don't know.

8. Which of the following statements is correct?

- Once one invests in a mutual fund, one cannot withdraw the money in the first year.

- Mutual funds can invest in several assets, for example invest in both stocks and bonds.

- Mutual funds pay a guaranteed rate of return which depends on their past performance.

- None of the above.

- Don't know.

9. If interest rates rise, what will typically happen to bond prices?

- Bond prices will rise.

- Bond prices will stay the same.

- Bond prices will fall.

- Don't know 
Table 1: Hypothesized influence of loss aversion on the willingness-to-accept and willingness-to-pay

\begin{tabular}{lccc}
\hline & good in possession & can be traded for & loss aversion will \\
\hline WTA & early retirement & money & increase WTA \\
WTP & money & early retirement & decrease WTP \\
\hline
\end{tabular}


Table 2: Online survey summary statistics

\begin{tabular}{lccc}
\hline Variable & Mean & (Median) & Std. Dev. \\
\hline Reservation Price & & & \\
Reservation Price - Level 1 (65\%) & 549.07 & $(300.00)$ & 835.95 \\
Reservation Price - Level 2 (110\%) & 973.84 & $(500.00)$ & 1544.45 \\
\hline Demographics & & & \\
Age & 40.37 & $(40.00)$ & 12.34 \\
Gender & 0.84 & & 0.36 \\
Income & $3,436.92$ & $(3,000.00)$ & $3,118.14$ \\
Number of Children & 0.79 & & 1.19 \\
High School Degree & 0.92 & & 0.27 \\
University Degree & 0.68 & & 0.47 \\
Married & 0.47 & & 0.50 \\
\hline Controls & & & \\
Risk Aversion (1-7) & 3.87 & & 1.47 \\
Loss Aversion (1-7) & 4.23 & & 0.60 \\
Financial Literacy Standard (0-4) & 3.51 & & 0.74 \\
Financial Literacy Extra (0-2) & 0.62 & & 8.12 \\
Life Expectancy (Males) & 83.33 & $(84.00)$ & 6.95 \\
Life Expectancy (Females) & 84.33 & $(85.00)$ & 50.77 \\
Planed Retirement Age (in month) & 777.14 & $(780.00)$ & 0.48 \\
Owns Private Pension Insurance & 0.64 & & 1.78 \\
Certainty of Social Security (1-7) & 2.97 & & \\
\hline
\end{tabular}




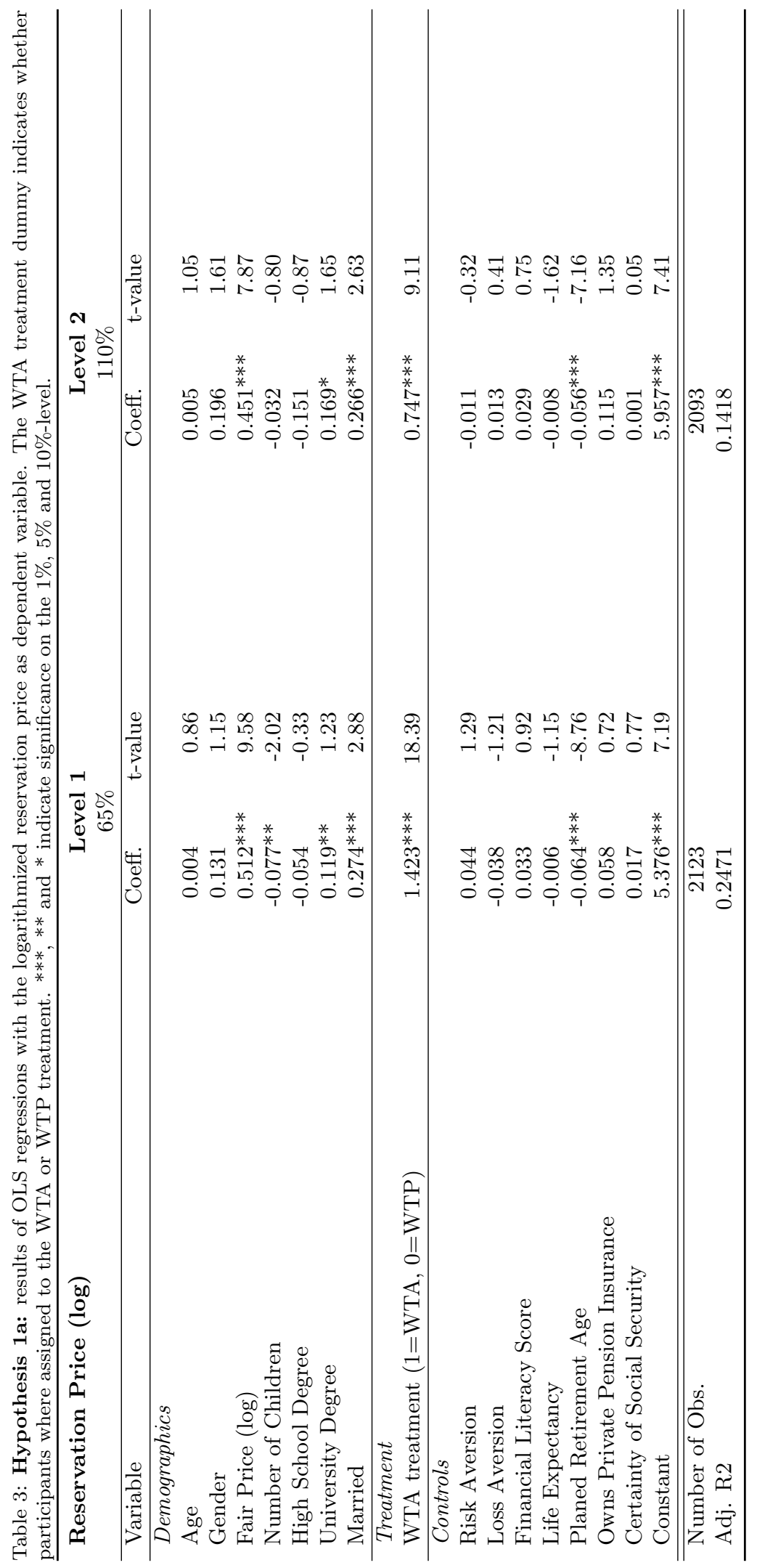




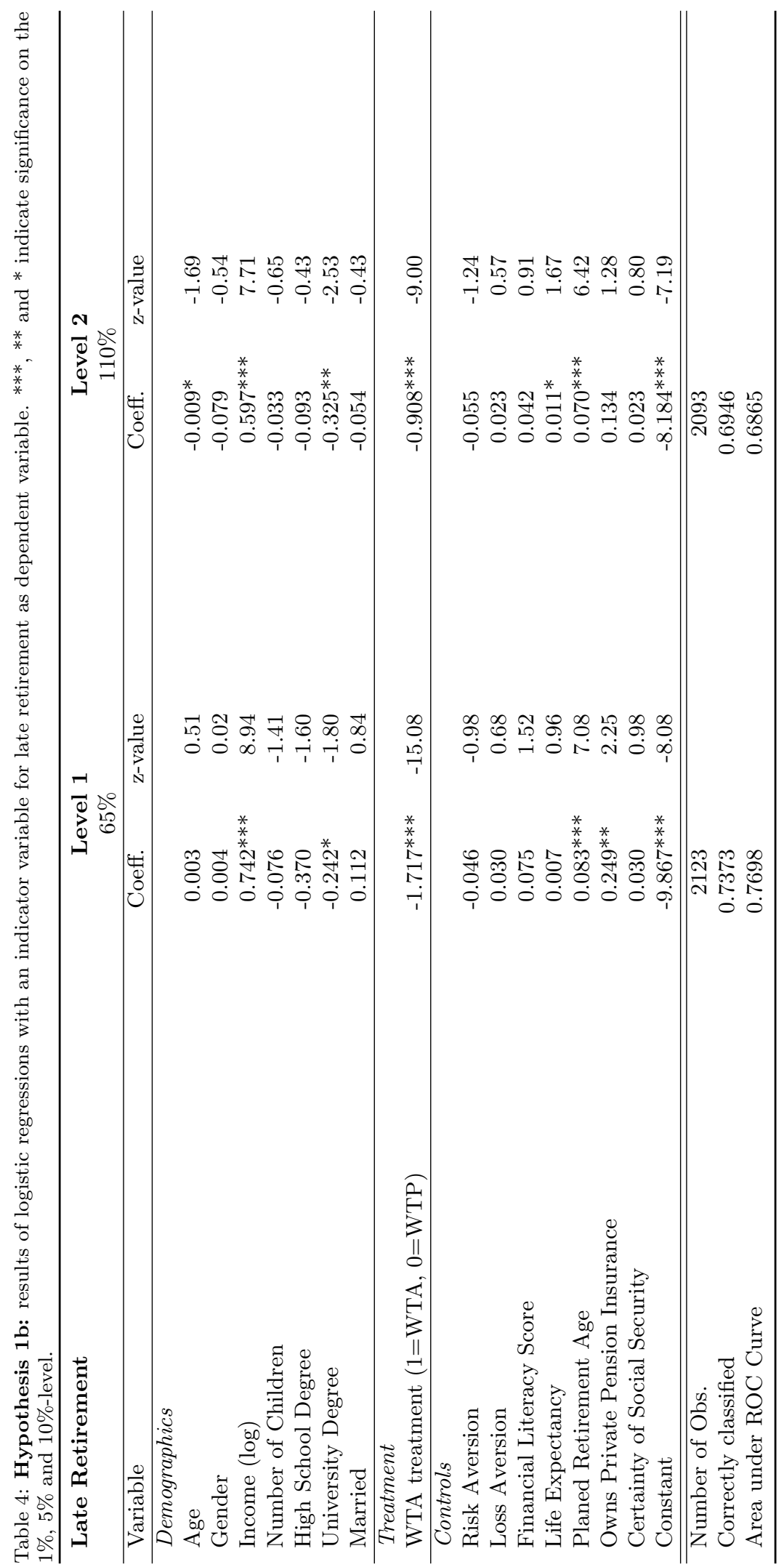




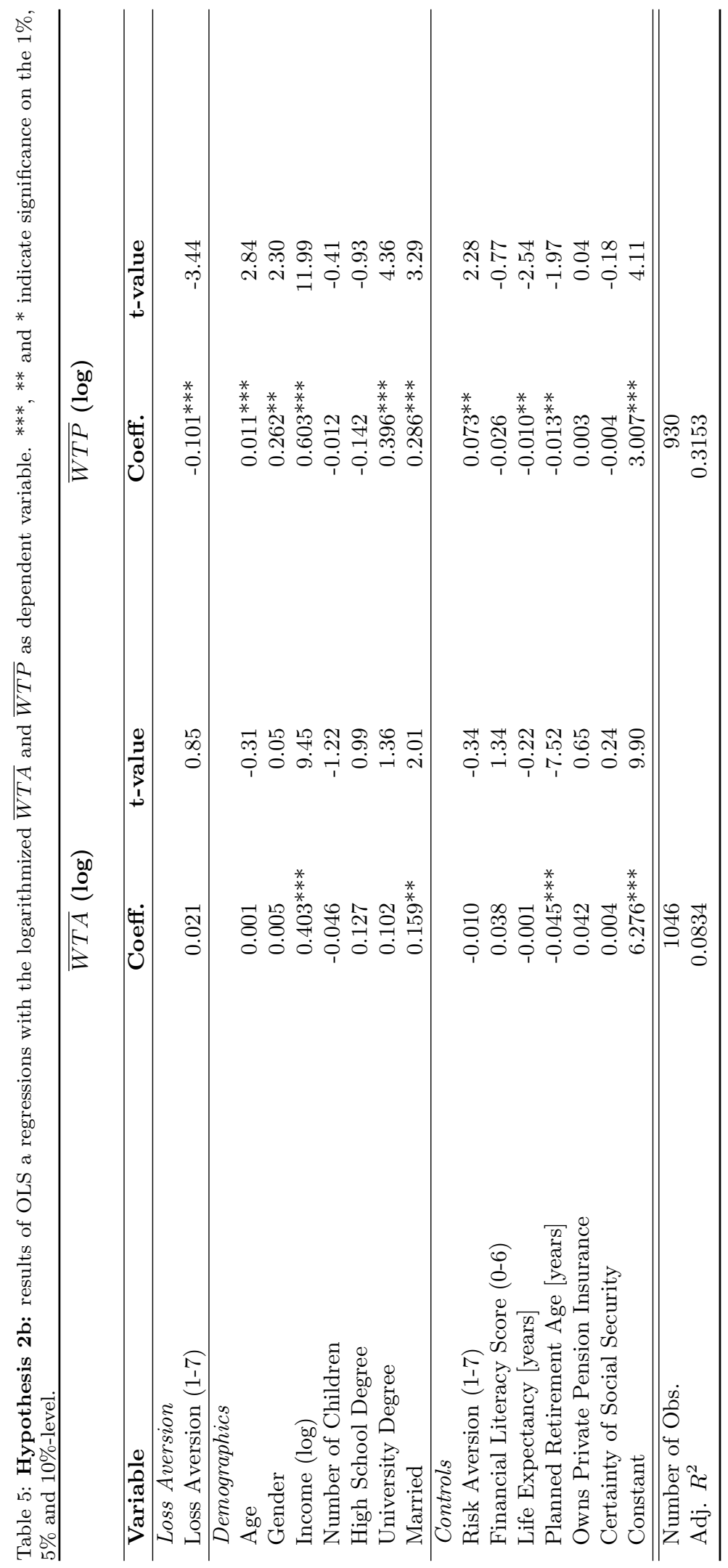




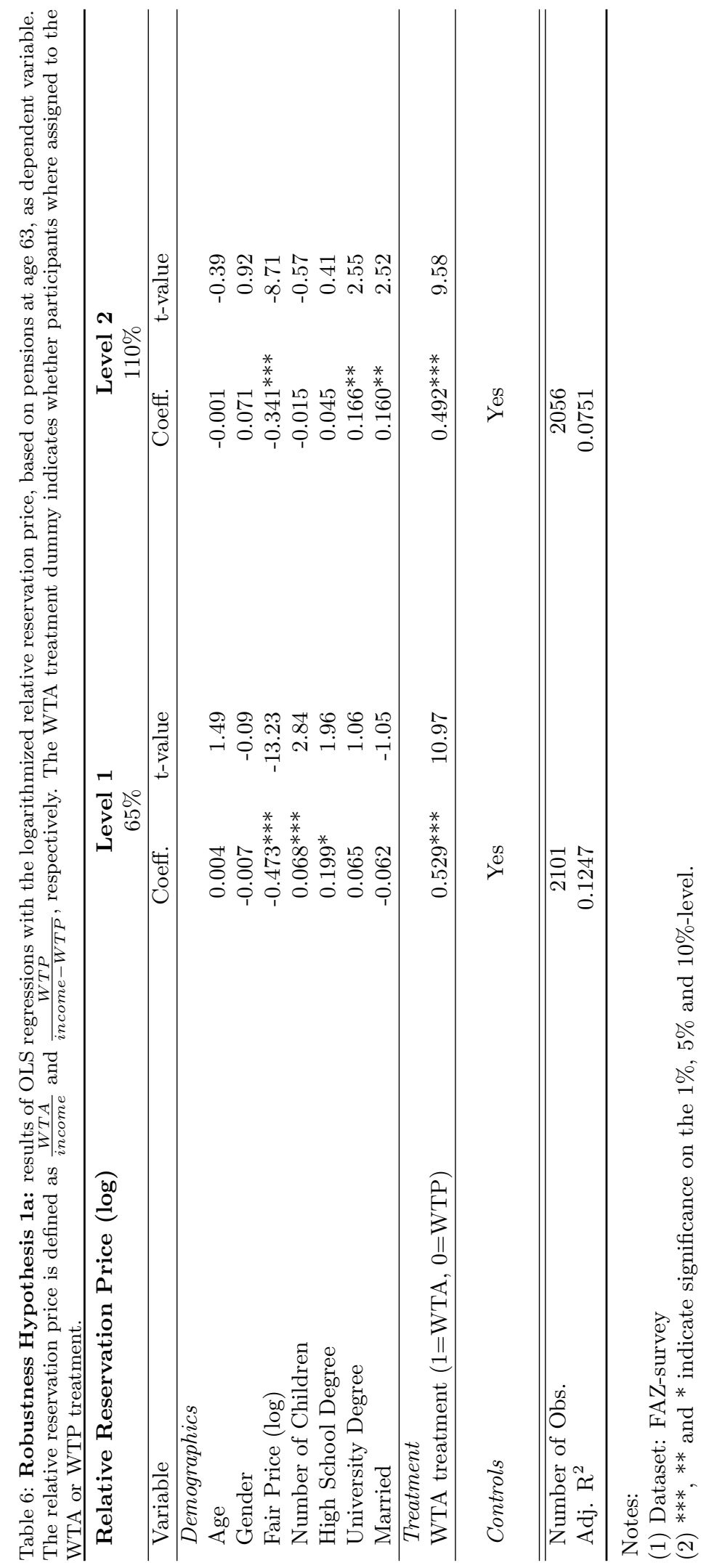




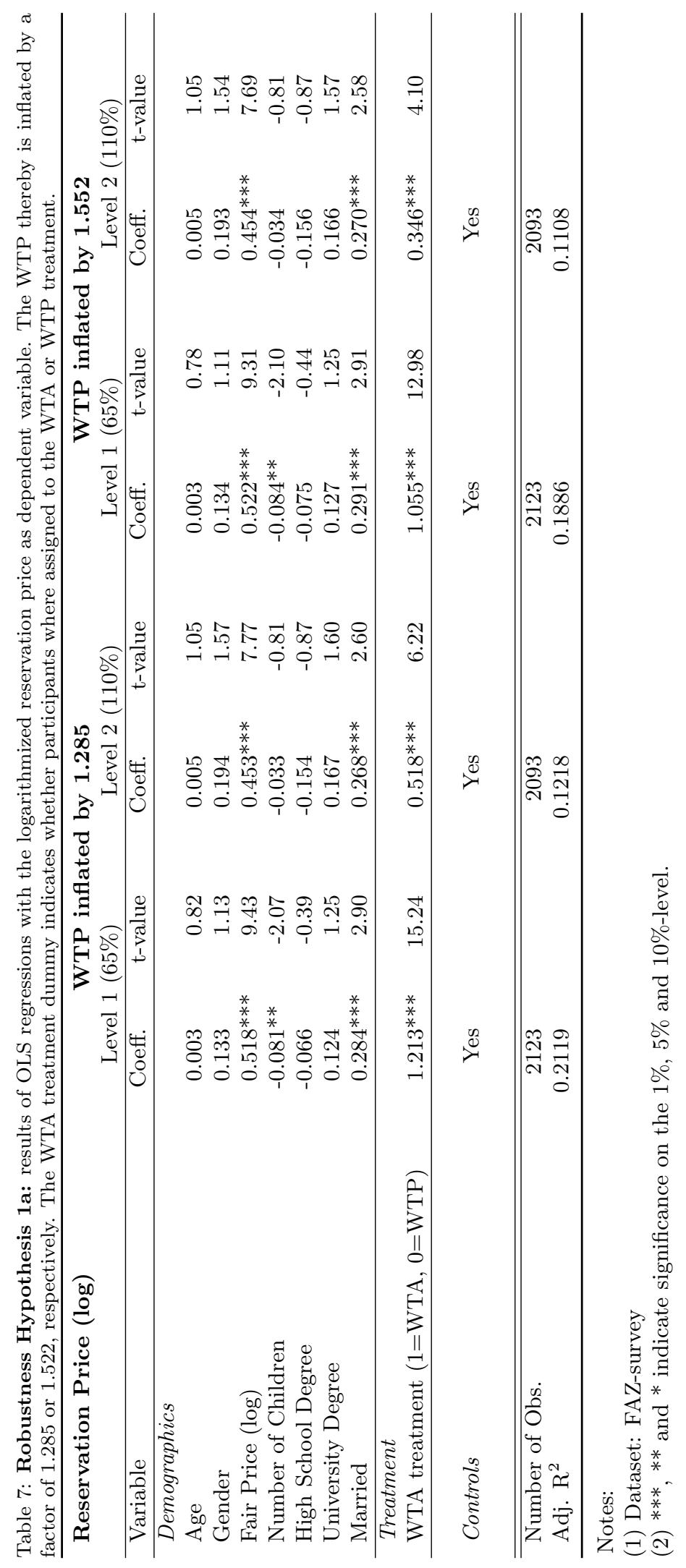




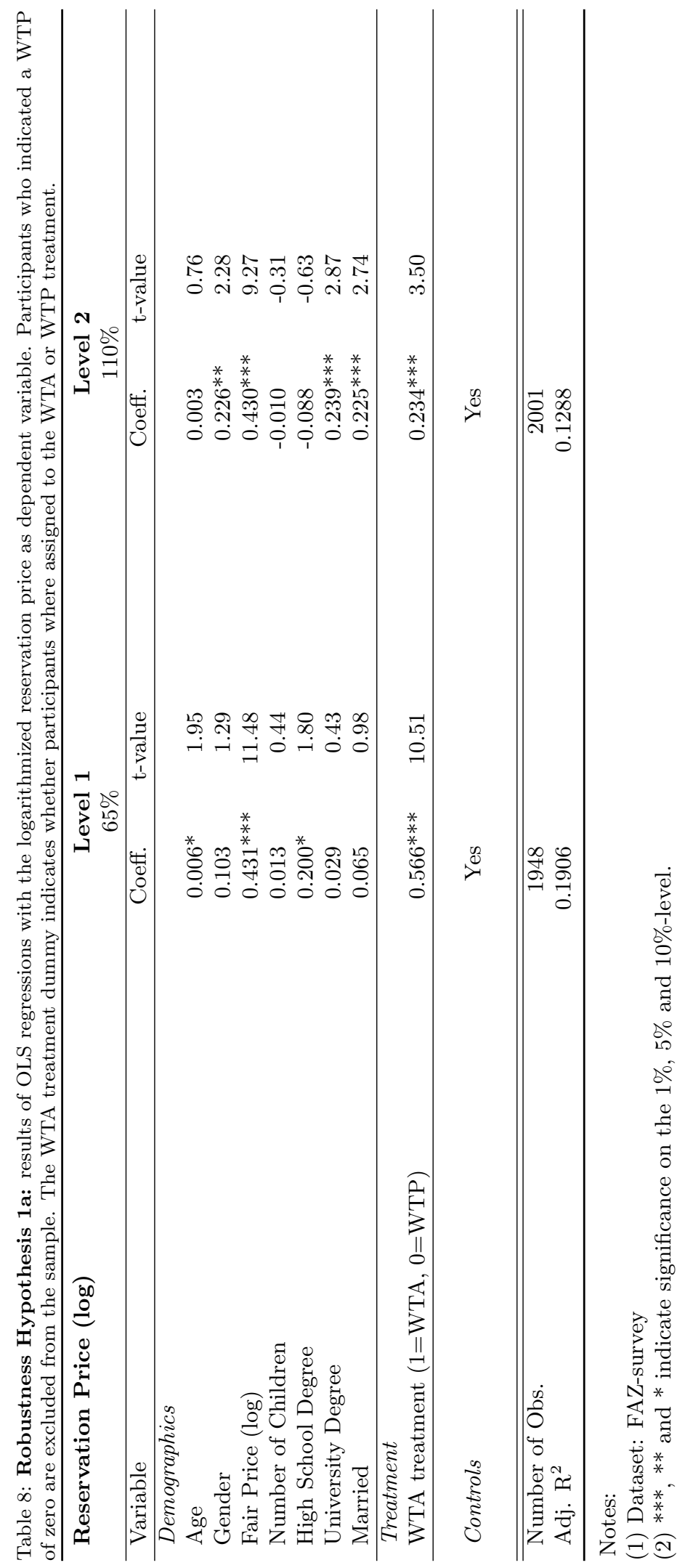


Table 9: Robustness - Hypothesis 1a: results of OLS regressions with the logarithmized reservation price for early retirement as dependent variable. The reservation price is measured in per cent of expected social security benefits per month. Data used for robustness is from the German SAVE panel, waves 2009 and $2011 / 2012$.***,** and $*$ indicate significance on the $1 \%, 5 \%$ and $10 \%$-level.

Reservation Price [\%]

\begin{tabular}{lcc}
\hline Variable & Coeff. & t-value \\
\hline Demographics & & -0.004 \\
Age & $-0.271^{* *}$ & -2.19 \\
Gender & 0.008 & 0.06 \\
Income (log) & -0.031 & -0.45 \\
Number of Children & -0.185 & -1.18 \\
High School Degree & -0.267 & -1.42 \\
University Degree & -0.130 & -0.86 \\
Married & & \\
\hline Treatment & $1.160^{* * *}$ & 9.13 \\
WTA treatment (1=WTA, 0=WTP) & & -0.66 \\
\hline Controls & -0.042 & -1.63 \\
Financial Literacy Score (0-9) & -0.013 & -2.67 \\
Life Expectancy & $-0.048^{* * *}$ & -0.76 \\
Planned Retirement Age (years) & -0.092 & 4.29 \\
Owns Private Pension Insurance & $6.437^{* * *}$ & \\
Constant & 240 & \\
\hline Avg. Number of Obs. & 225 & \\
Avg. Number of Clusters & 0.3489 & \\
Avg. Adj. R & & \\
\hline Note: & & \\
\hline
\end{tabular}

Notes:

(1) The SAVE data is multiply imputed with five different implicates. All five implicates are used.

(2) Coefficients and standard errors are calculated according to Rubin (1987). 
Table 10: Robustness - Hypothesis 1b: results of logistic regressions with an indicator variable for late retirement as dependent variable. Data used for robustness is from the German SAVE panel, waves 2009 and $2011 / 2012 . * * *, * *$ and $*$ indicate significance on the $1 \%, 5 \%$ and $10 \%$-level.

\section{Late Retirement}

\begin{tabular}{lcc}
\hline Variable & Coeff. & z-value \\
\hline Demographics & -0.019 & -1.02 \\
Age & $0.646^{*}$ & 1.82 \\
Gender & 0.385 & 0.81 \\
Income (log) & 0.037 & 0.20 \\
Number of Children & -0.170 & -0.37 \\
High School Degree & 0.741 & 1.35 \\
University Degree & 0.128 & 0.30 \\
Married & & \\
\hline Treatment & $-2.300^{* * *}$ & -6.01 \\
WTA treatment (1=WTA, 0=WTP) & \\
\hline Controls & 0.030 & 0.17 \\
Financial Literacy Score (0-9) & -0.001 & -0.03 \\
Life Expectancy & $0.102^{*}$ & 1.89 \\
Planned Retirement Age (years) & $0.574^{*}$ & 1.73 \\
Owns Private Pension Insurance & $-9.141^{*}$ & -1.81 \\
Constant & 240 & \\
\hline \hline Avg. Number of Obs. & 225 & \\
Avg. Number of Clusters & 0.7114 & \\
Avg. Correctly classified & 0.7905 & \\
Avg. Area under ROC Curve &
\end{tabular}

Notes:

(1) The SAVE data is multiply imputed with five different implicates. All five implicates are used.

(2) Coefficients and standard errors are calculated according to Rubin (1987). 